NBER WORKING PAPER SERIES

\title{
WHO UNDERREACTS TO CASH-FLOW NEWS? \\ EVIDENCE FROM TRADING BETWEEN INDIVIDUALS AND INSTITUTIONS
}

\author{
Randolph B. Cohen \\ Paul A. Gompers \\ Tuomo Vuolteenaho \\ Working Paper 8793 \\ http://www.nber.org/papers/w8793 \\ NATIONAL BUREAU OF ECONOMIC RESEARCH \\ 1050 Massachusetts Avenue \\ Cambridge, MA 02138 \\ February 2002
}

\begin{abstract}
We would like to thank Nicholas Barberis, Alon Brav, Timothy Burch, John Campbell, John Heaton, Matti Keloharju, Owen Lamont, Rafael Laporta, Christopher Polk, Andrei Shleifer, Erik Stafford, Jeremy Stein, Bhaskaran Swaminathan, Kent Womack (a discussant), and two anonymous referees for helpful comments. The paper has also benefited from the comments of the participants at the Chicago Quantitative Alliance spring meeting, Federal Reserve Bank of New York finance workshop, Harvard University Department of Economics finance seminar, MIT Sloan School of Management finance brown-bag lunch and finance seminar, NBER Behavioral Finance working group meeting, and Stanford Business School finance seminar. Errors and omissions remain our responsibility. The views expressed herein are those of the authors and not necessarily those of the National Bureau of Economic Research.
\end{abstract}

(C) 2002 by Randolph B. Cohen, Paul A. Gompers and Tuomo Vuolteenaho. All rights reserved. Short sections of text, not to exceed two paragraphs, may be quoted without explicit permission provided that full credit, including (C) notice, is given to the source. 
Who Underreacts to Cash-Flow News?

Evidence from Trading between Individuals and Institutions

Randolph B. Cohen, Paul A. Gompers and Tuomo Vuolteenaho

NBER Working Paper No. 8793

February 2002

JEL No. G120, G140

\begin{abstract}
A large body of literature suggests that firm-level stock prices "underreact" to news about future cash flows, i.e., shocks to a firm's expected cash flows are positively correlated with shocks to expected returns on its stock. We estimate a vector autoregession to examine the joint behavior of returns, cash-flow news, and trading between individuals and institutions. Our main finding is that institutions buy shares from individuals in response to good cash-flow news, thus exploiting the underreaction phenomenon. Institutions are not simply following price momentum strategies: When price goes up in the absence of positive cash-flow news, institutions sell shares to individuals. Although institutions are trading in the "right" direction, institutions as a group outperform individuals by only 1.44 percent per annum before transaction and other costs, because they are extremely conservative in deviating from the value-weight market index.
\end{abstract}

Randolph B. Cohen

Harvard Business School

Boston, MA 02163

Paul A. Gompers

Harvard Business School and the NBER

Boston, MA 02163

pgompers@hbs.harvard.edu

Tuomo Vuolteenaho

Harvard University and the NBER

Cambridge, MA 02138

t_vuolteenaho@harvard.edu 
An emerging body of empirical literature suggests that stock prices "underreact" to new information about firms' cash flows. Events that are a priori likely to contain cash-flow-relevant information, such as earnings surprises and dividend initiations and omissions, are followed by a stock-price drift in the same direction as the initial announcement return. ${ }^{1}$ While some researchers (e.g., Fama (1998)) argue that these empirical findings are sample-specific chance results, others have tried to devise behavioral models to explain them (Barberis, Shleifer, and Vishny (1998), Daniel, Hirshleifer, and Subrahmanyam (1998), and Hong and Stein (1999)).

This paper uses a highly stylized vector autoregression (VAR) to offer additional evidence on investor heterogeneity and underreaction. By definition, a firm's stock returns are driven by shocks to expected cash flows (i.e., cash-flow news) and/or by shocks to expected returns (i.e., expected-return news) (Campbell (1991)). Vuolteenaho's (2002) firm-level VAR results show that the immediate price response to firm-level cash-flow news is less than one-for-one, consistent with the underreaction pattern found in many event studies. Our contribution is to measure the response of institutional ownership to cash-flow news, thus documenting whether the institutions as a group trade to exploit the underreaction phenomenon. In addition, we explore a more general research question: Does institutional trading push prices towards fundamental values or away from them?

Our main findings are easily summarized. First, institutions respond to positive cash-flow news by buying shares from individual investors, thus exploiting the underreaction pattern. According to the VAR, 25 percent cash-flow news results in institutions buying approximately 2 percent of the shares outstanding. Considering that the average stock has a cash-flow-news standard deviation of 47 percent and institutional ownership of 36 percent, this response is economically significant. Second, we find that institutions are not simply following price-momentum strategies. When the stock price increases 25 percent in the absence of any cash-flow news, institutions sell approximately 5 percent of the shares outstanding to individuals. Third, the response of institutional ownership to cash-flow news is weaker for small stocks. Since small stocks also exhibit the strongest underreaction patterns, this finding is consistent with institutions facing exogenous constraints in trading small stocks. As a result of these trading patterns, the institutional overweight of a stock has a 0.64 estimated correlation with the stock's long-horizon expected abnormal return. 
To answer the above research questions, it is necessary to jointly model the rich time-series dynamics of prices, cash flows, and institutional ownership. Table I illustrates this point with our data. In Panel A, we use a naïve approach and independently sort stocks into cells based on accounting returns (ROEs) and stock returns. For each cell, we measure the average contemporaneous change in institutional ownership. Controlling for the stock return, institutional buying is stronger for stocks with high accounting returns. The naïve approach is thus able to show that institutions prefer to buy stocks with positive cash-flow news.

The naïve approach in Panel A of Table I also shows that, controlling for the accounting return, institutions prefer to buy stocks with higher (contemporaneous) stock returns. Since institutional buying appears to be correlated with the component of the stock return that cannot be explained by the contemporaneous accounting return, it is tempting to conclude from Panel A that institutional buying occasionally pushes prices above the fundamental values. However, such reasoning implicitly assumes that the current accounting return is a perfect proxy for all new information about all future cash flows. Since past stock returns and changes in institutional ownership forecast future profitability in our data, this implicit assumption is clearly false. It is thus difficult to draw strong conclusions along these lines from Panel A.

This is where our VAR methodology pays off: We use the VAR model to compute a measure of cash-flow news that better captures the new information about all future cash flows. Panel B of Table I repeats the sort using our VAR cash-flow-news measure in place of the naïve cash-flow measure of Panel A. Using the VAR cash-flow-news measure strengthens the conclusion that institutions buy on cash-flow news, controlling for contemporaneous stock return. More importantly, when the VAR cash-flow news is used as the cash-flow proxy, the cash-flow proxy drives the marginal relation between institutional buying and contemporaneous stock returns from positive to negative. The more complicated VAR approach is necessary, because the use of a better cash-flow-news proxy reverses the evidence suggesting that institutional buying coincides with a stock becoming more expensive relative to cash-flow fundamentals. ${ }^{2}$

This study connects to the previous literature at a number of points. A large body of empirical literature investigates the investment behavior of institutions, and our paper both builds on and adds to this evidence. First, Lakonishok, Shleifer, and Vishny (1992a), Grinblatt, Titman, and Wermers (1995), Wermers (1999, 2000), Nofsinger and Sias (1999), Grinblatt and Keloharju (2000a, b), and others show that institutional buying and stock returns are contemporaneously correlated. Our paper qualifies this result 
further by showing that only the permanent component of return (i.e., cash-flow news) is positively correlated with institutional buying. Second, Daniel, Grinblatt, Titman, and Wermers (1997), Wermers (1999), Nofsinger and Sias (1999), Grinblatt and Keloharju (2000a, b), Chen, Jegadeesh, and Wermers (2000), Gompers and Metrick (2001), and others find evidence that the short-term expected returns are higher (lower) for stocks that have recently been subject to significant institutional buying (selling). By using the present-value framework and our VAR, we extend these short-horizon return-predictability findings to statements about the level of prices. Third, Del Guercio (1996), Falkenstein (1996), Gompers and Metrick (2001), and others document institutional preferences for certain types of security and/or firm characteristics. The VAR model of this paper provides a tool for describing the short-run and long-run dynamics of these preferences and their relation to the price-formation process.

The VAR results also have relevance to theories hypothesizing that institutional investors follow destabilizing positive-feedback trading strategies (Lakonishok, Shleifer, and Vishny (1992a) and others). According to our findings, cash-flow news is the component of contemporaneous return that is positively correlated with institutional buying. Under the plausible working assumption that cash-flow news is exogenous (i.e., returns and/or ownership structure do not cause the expected cash flows), this buying cannot feed back in a destabilizing way. The positive correlation of institutional ownership and expectedreturn news also suggests that institutions do not follow positive-feedback investment strategies, although one cannot directly infer causality from this correlation.

Our cross-sectional analysis is largely in agreement with Cohen's (2000) time-series analysis. Cohen examines the aggregate institutional and individual portfolio stock-bond allocations and shows that institutions tend to buy stocks from individuals when expected returns go up. Like Cohen's, our results suggest that to the extent that the aggregate trading of institutions affects asset prices, these effects are unlikely to be deleterious to the efficient functioning of the capital markets. On the contrary, institutional trades appear to reduce the cross-sectional differences between the long-run expected returns on different stocks, thus should not tend to be destabilizing.

It is also interesting to relate our results to the literature on the investment performance of money managers. The previous literature can be summarized as reaching two conclusions. First, the institutions do not deliver superior performance (relative to passive benchmarks) to their clients (Jensen (1968), Lakonishok, Shleifer, and Vishny (1992b), and others). This first conclusion is statistically strong if net 
returns are examined, and less strong if returns are recorded gross of fees but net of trading costs. Second, studies that examine the pure stock-selection ability of institutions have found that the average institution has stock-selection ability, i.e., institutions overweight stocks that have high (short-term) expected return, and underweight stocks with low expected return (Daniel, Grinblatt, Titman, and Wermers (1997), Wermers (2000), Gompers and Metrick (2001), and others). The second conclusion is statistically significant and obtained across different data sets, including ours.

Daniel, Grinblatt, Titman, and Wermers (1997) reconcile these two findings: "The evidence ... suggests that the average mutual fund does, in fact, succeed [in picking stocks that outperform simple mechanical rules.] However, we find that the amount by which the average mutual fund beats a mechanical strategy is fairly small (under 100 basis points) and is approximately equal to the average management fee." As a result, the superior stock-picking ability of institutions does not show up as superior performance after fees and/or trading costs.

We contribute to the literature on the investment performance of money managers by further evaluating the information content of institutional portfolio allocations. According to the estimated VAR, the fraction of institutional ownership has 0.64 correlation with the unrestricted VAR estimate of longhorizon abnormal return. Yet, the correlation of the weights of the aggregate institutional portfolio and CRSP value-weight portfolio is 0.923 and return correlation of these two portfolios 0.998 . Our interpretation of these correlation estimates is twofold: First, the quality of information possessed by the institutions in the aggregate is high relative to the established return-predictability phenomena identified in the academic literature. Second, although institutions as a group trade in the right direction, the deviations of the aggregate institutional portfolio from the CRSP value-weight market portfolio are very small. In the aggregate, institutions use their high-quality information extremely conservatively.

Why do institutions in the aggregate trade in a very conservative manner? One possible explanation is that institutions may simply make the same types of errors as individuals in underreacting to cash-flow news, but make these errors to a lesser degree. A second explanation may be that institutions recognize the opportunity presented by underreaction to cash-flow news, but are unable to take full advantage of it due to some significant constraints, such as those suggested by Shleifer and Vishny (1997). For example, due to the open-ended structure of most asset-management organizations, institutional investors may be greatly concerned with tracking a benchmark. Also, fund managers often limit their potential holdings by written 
and unwritten rules, possibly to eliminate potential agency concerns. A third possible explanation is heterogeneity of institutional investors, either in their expertise or investment mandates. For example, if two sector-fund managers understand the joint distribution of securities' returns in their own sector and choose portfolios that are optimal for those who invest only in their sector, no portfolio of the two funds is likely to be a globally optimal portfolio.

The rest of the paper is organized as follows. Section I outlines the VAR methodology for measuring underreaction and shows the empirical patterns of how price and institutional ownership respond to cashflow news. Section II discusses our results and explores possible explanations. Section III shows the results of additional robustness checks. Section IV concludes.

\section{Measuring the reaction of stock price and institutional ownership to cash-flow news}

We measure over- and underreaction to cash-flow news using Campbell's (1991) returndecomposition methodology. We use a VAR to empirically decompose the unexpected stock return into two components: cash-flow and expected-return news. Within this decomposition, cash-flow news is the return that would have realized if expected returns had not changed. Our measure of over- and underreaction is the regression coefficient of realized stock return on contemporaneous cash-flow news. A regression coefficient greater than unity corresponds to overreaction and a coefficient less than unity to underreaction. The VAR also enables us to measure the correlation of shocks to institutional ownership with expected-return and cash-flow news.

\section{A. Return-decomposition framework}

Campbell (1991), Vuolteenaho (2002), and others decompose the unexpected stock return into an expected-return component and a cash-flow component:

$$
r_{t}-E_{t-1} r_{t}=\Delta E_{t} \sum_{j=0}^{\infty} \rho^{j} e_{t+j}-\Delta E_{t} \sum_{j=1}^{\infty} \rho^{j} r_{t+j}+\kappa_{t},
$$

where $\Delta E_{t}$ denotes the change in expectations from $t-1$ to $t$ (i.e., $\left.E_{t}(\cdot)-E_{t-1}(\cdot)\right), e_{t}$ the $\log$ accounting return on equity (ROE), $r_{t}$ the log stock return, and $\kappa$ the approximation error. $\rho$ is a constant set to 0.97 . (The details of the derivation of equation (1) and the choice of $\rho$ are reproduced in Appendix 1.) We defining the two return components as cash-flow news $\left(N_{c f}\right)$ and expected-return news $\left(N_{r}\right)$ :

$$
N_{c f, t} \equiv \Delta E_{t} \sum_{j=0}^{\infty} \rho^{j} e_{t+j}+\kappa_{t}, \quad N_{r, t} \equiv \Delta E_{t} \sum_{j=1}^{\infty} \rho^{j} r_{t+j} .
$$


Since $r_{t}-E_{t-1} r_{t}=N_{c f, t}-N_{r, t}$, the unexpected stock return can be high if either expected returns decrease and/or expected future ROEs increase. ${ }^{3}$ When price goes up, the price increase must either be followed by high cash flows or the price must come back down. If expected returns remain constant, unexpected return equals cash-flow news.

Campbell's (1991) return decomposition is related to the Beveridge-Nelson (1981) decomposition in the time-series literature. The Beveridge-Nelson decomposition separates a time series into two additive components, a random walk and a stationary component. If $\rho$ is set to 1 in equation (2), cash-flow news corresponds to the shock to the random-walk component of the log stock price and expected-return news to the shock to the stationary component of the log stock price. According to this interpretation, the cash-flow news is a shock to the long-run "price-target trend" that the stock price is expected to approach.

An adaptation of the familiar present-value formula can be used to illustrate the intuition behind this return decomposition. According to the present-value formula in equation (3), an asset's price equals the discounted present value of its expected future cash flows plus a pricing error:

$$
P_{t-1}=\sum_{i=0}^{\infty}\left\{\frac{E_{t-1}\left(C F_{t+i}\right)}{\prod_{j=0}^{i}\left(1+K_{t+j}\right)}\right\}+\varepsilon_{t-1},
$$

where $P$ denotes price, $C F$ cash flow, $K$ fair risk-adjusted discount rate, and $\varepsilon$ pricing error. Clearly, the price can increase if expected cash flows increase and/or fair discount rates decrease and/or the pricing error increases. In Campbell's (1991) return decomposition, cash-flow news corresponds approximately to the percentage price change due to the change in expected cash flows, or the return that would have realized if the discount rates and pricing error had not changed. Expected-return news is the percentage price change due to changes in discount rates and/or in the pricing error.

Of course, Campbell's (1991) return decomposition is a purely mechanical construct and requires minimal assumptions about the behavior of the market participants. Typically, the return and ROE expectations in equations (1) and (2) must be estimated from the data and will, therefore, reflect the econometrician's method of forming these expectations. Interpretation of the estimated news terms requires more assumptions. As the first set of working assumptions, we assume that the VAR process correctly describes the evolution of rationally formed conditional expectations and that the fair discount rates are constant across stocks (but not over time). Under these assumptions, the estimated market-adjusted 
expected-return-news series reflects biases in the market's pricing process and would perhaps better be labeled as "mispricing news."

Of course, assuming that market-adjusted expected-return news is solely due to mispricing-induced return predictability is solely dependent on one's prior beliefs. Alternatively, one could take the view that market-adjusted expected-return news is driven by firm-specific risk-induced variation in fair discount rates.

\section{B. Defining over- and underreaction}

Following Vuolteenaho (2002), we define over- and underreaction to cash-flow news in terms of a simple regression coefficient. We make two working assumptions: First, we assume that, at any point of time, the "fair" discount rates are equal across all stocks. This assumption enables us to identify marketadjusted expected-return news as being solely due to changes in the pricing error. Second, we assume that cash-flow news is exogenous, i.e., that the discount rates and/or pricing error do not cause cash-flow news.

Under these assumptions, one can raise the question whether the market's reaction to the relevant cash-flow news is excessive, correct, or insufficient. We define overreaction as $b>1$ in the following regression:

$$
\widetilde{r}_{t}=a+b \widetilde{N}_{c f, t}+w_{t}
$$

Conversely, the underreaction case corresponds to $b<1$ and the correct-reaction case to $b=1$. In words, if good cash-flow news typically results in the stock becoming more overpriced (or less underpriced,) we call this overreaction. Conversely, if good cash-flow news on average results in less overpriced (or more underpriced) stock, we call this underreaction.

For example, consider a stock worth $\$ 100$. If there is news that all expected cash flows are 15 percent higher (while holding the risk and fair discount rates constant), an unbiased or correct stock-price reaction is 15 percent return and $\$ 115$ stock price (assuming no dividends). If the stock-return and price response to such news are typically 10 percent and $\$ 110, b<1$ and it is reasonable to call this price behavior underreaction.

Our bivariate definition of over- and underreaction that considers the joint process of returns and cash-flow news differs from the definitions adopted by many other empirical studies. For example, DeBondt and Thaler (1985) examine the univariate autocovariance function of returns and infer overreaction from long-horizon negative autocorrelation. However, our definition of over- and underreaction has the following advantages over the univariate approach. First, as noted by Campbell 
(1991) and Vuolteenaho (2002), a univariate time-series approach cannot unambiguously estimate both the variance of expected-return news and the regression coefficient of return on cash-flow news. It is possible that the price responds less than one-for-one to cash-flow news, yet returns are negatively autocorrelated. This is because any type of transitory mispricing (including pure noise) can cause long-horizon negative autocorrelation in stock returns. Second, our definition is capable of separating underreaction from delayed overreaction. If the price initially overreacts $(b>1)$ but this overreaction is followed by future price movements in the same direction, many alternative approaches incorrectly classify this pattern as underreaction.

\section{Implementation using the VAR methodology}

A vector autoregression (VAR) provides a convenient way to implement the return decompositions. Let $z_{i, t}$ be a vector of firm-specific state variables describing a firm $i$ at time $t$. In particular, let the first element of $z_{i, t}$ be the firm's market-adjusted log stock return. An individual firm's state vector is assumed to follow a linear law:

$$
z_{i, t}=\Gamma z_{i, t-1}+u_{i, t} .
$$

The error term $u_{i, t}$ is assumed to have a covariance matrix $\Sigma$ and to be independent of everything known at $t-1$. Most of our specifications restrict the VAR parameters to be constant over time and across firms, but some of our specifications will relax this restriction by allowing for cross-sectional variation in the VAR parameters. All of our standard-error computations allow for general correlation structure of errors across firms.

The VAR implies a return decomposition. Define $e 1^{\prime} \equiv\left[\begin{array}{llll}1 & 0 & \cdots & 0\end{array}\right]$ and

$$
\lambda^{\prime} \equiv e 1^{\prime} \rho \Gamma(I-\rho \Gamma)^{-1} .
$$

The definition (6) introduced by Campbell (1991) simplifies the expressions considerably: Expected-return

news can now be conveniently expressed as $\lambda^{\prime} u_{i, t}$ and cash-flow news as $\left(e 1^{\prime}+\lambda^{\prime}\right) u_{i, t}$. If returns are unpredictable, i.e., the first row of $\Gamma$ is zeros, expected-return news is identically zero and the entire return is due to cash-flow news.

Effectively, Campbell's (1991) method first computes expected-return news directly and then backs out the cash-flow news as unexpected return plus expected-return news. It may seem that this indirect method of calculating cash-flow news as a residual relies on heavier assumptions than does directly calculating the change in the discounted sum of clean-surplus ROEs. The robustness-checks section III.C 
uses the clean-surplus ROE directly and shows that the results are robust to the choice between these two alternatives. Also, setting $\rho$ equal to 1 , which results in cash-flow news being equal to the shock to the permanent component of the log stock price and expected-return news being equal to the shock to the temporary component of the log stock price, does not alter our stated results.

Finally, our measure of over- and underreaction, the regression coefficient of the total stock return on cash-flow news, can be computed from the VAR parameters using a simple formula: $1-\lambda \Sigma(e 1+\lambda) /\left[\left(e 1^{\prime}+\lambda^{\prime}\right) \Sigma(e 1+\lambda)\right]$. This formula is derived by recognizing that the total return equals conditional expected return plus cash-flow news less expected-return news and that the conditional expected return is independent of the news terms.

Implementing the regression (4) via a time-series model may appear fragile in its sensitivity to sampling and model misspecification errors. However, when cash-flow news and the regression coefficient in equation (4) are estimated using Campbell's (1991) return decomposition, the approach is surprisingly robust. When Campbell's return decomposition is used, the sampling and/or model specification error in the estimated cash-flow-news term is not independent of the stock return. Thus, the usual errors-invariables intuition about coefficient attenuation does not apply to this case. In effect, Campbell's methodology gives the benefit of the doubt to cash-flow news: The VAR allocates the entire return to cashflow news unless it finds evidence of the return reversing. Under the assumption that the estimated variance of cash-flow news is not zero, the VAR-model implies $b<1$ if and only if the estimated correlation of expected-return news and cash-flow news is positive. In other words, the VAR model indicates underreaction if and only if it can identify return predictability that is positively related to recent good news about cash flows. In the extreme, if the model is so misspecified that stock returns appear unpredictable, the regression coefficient in equation (4) will take the value 1, implying neither under- nor overreaction.

\section{Data and the selected VAR specification}

We obtain our empirical results from a firm-level panel (the CRSP-COMPUSTAT intersection linked to the SPECTRUM database of institutional holdings). Our final sample covers the period 1983-1998 (16 years) and consists of 23,501 firm-years. Table II and Figure 1 show descriptive statistics and Appendix 2 contains the details of data sources and variable definitions.

We consider a parsimonious VAR specification that uses market-adjusted log stock return, log bookto-market, log GAAP ROE, and fraction of institutional ownership as the state variables. Only one lag of 
each is used to predict the state-vector evolution. This four-variable VAR specification is designed to capture the following empirical return-predictability results. Historically, past long-term losers have outperformed past long-term winners ("long-term reversal," DeBondt and Thaler (1985)), while past shortterm winners have outperformed past short-term losers ("momentum," Jegadeesh and Titman (1993, 2001)). High book-to-market-equity firms have earned higher average stock returns than low book-to-market-equity firms ("book-to-market anomaly," Rosenberg, Reid, and Lanstein (1985) and others). Controlling for other characteristics, firms with higher profitability have earned higher average stock returns (Haugen and Baker (1996)). Finally, institutional ownership predicts one-period returns (Wermers (1999) and others).

The results of Vuolteenaho (2002) suggest that a similar simple specification adequately captures the features of the data that are important to the computation of the news terms. Consistent with this finding, we document in the robustness-checks section III.D that our main results are not sensitive to a number of changes in the VAR specification.

We begin by using robust and simple methods - the weighted least squares (WLS) approach and one pooled prediction regression per state variable - in estimating the VAR parameters. Instead of using the optimal but unknown generalized least squares (GLS) weights or unit ordinary least squares (OLS) weights, we weigh each cross-section equally, much as the Fama-MacBeth (1973) procedure does. In practice, this means deflating the data for each firm-year by the number of firms in the corresponding cross-section. (The main findings of the paper are not sensitive to the choice between pooled-OLS, pooled-WLS, or FamaMacBeth procedures.) We use two methods to calculate cross-correlation-consistent standard errors: Rogers' (1983, 1993) robust standard-error method and Shao and Rao's (1993) jackknife method. (Vuolteenaho (2002) discusses the details of these procedures.)

The pooled-WLS parameter estimates (presented in Panel A of Table III) imply that expected returns are high when past one-year return, the book-to-market ratio, profitability, and institutional ownership are high. Our result that institutional ownership predicts returns after controlling for other stock characteristics is consistent with the empirical results of Wermers (1999, 2000), Gompers and Metrick (2001), Pirinsky (2000), and others. Expected profitability is also high when past stock return, profitability, and institutional ownership are high. In summary, our VAR parameter estimates are of sign and magnitude consistent with previous research. 
We also estimate VAR models allowing for firm-specific variation in the VAR parameters. Since we do not impose any forward-looking survival requirements, many of our firms have very short time series. Estimating separate VAR parameters for each firm using OLS or WLS is, therefore, infeasible. Instead of computing firm-by-firm OLS or WLS estimates, we follow Swamy's (1970) random-coefficient-model (RCM) approach. RCM is based on the assumption that firms' VAR parameters are random variables drawn from a common distribution. The parameters of this common distribution, dubbed hyperparameters, are estimated with maximum likelihood. Given these hyperparameters, maximum-likelihood predictors of individual firms' VAR parameters can be computed using the prior-likelihood approach of Lee and Griffiths (1979). The prior-likelihood approach uses the estimated population distribution of coefficients as the prior information and uses the Bayes' rule to compute posterior-mean predictions of the firm-specific coefficients.

In our RCM implementation, firm i's data are assumed to be generated from a VAR model:

$$
z_{i, t}=\mathrm{A}_{i}+\Gamma_{i} z_{i, t-1}+u_{i, t}, \quad u_{i, t} \sim \text { i.i.d.N }\left(0, \Sigma_{i}\right) .
$$

Firm i's intercept vector and transition matrix are assumed to be drawn from the distribution:

$$
\operatorname{vec}\left(\left[\mathrm{A}_{i} \Gamma_{i}\right]^{\prime}\right) \sim \text { i.i.d.N }(\mu, \Omega) .
$$

The firm-specific covariance matrices are treated as fixed parameters. Appendix 3 shows the details of the maximum-likelihood estimation algorithm.

Panel B of Table III shows the VAR model for the "average" firm, i.e., the VAR model that corresponds to the mean of the coefficient distribution, $\mu$. The RCM-mean VAR parameters are similar to the pooled-WLS estimates. As with the pooled-WLS estimates, the RCM hyperparameter estimates suggest that the average firm's dynamics include the return-predictability phenomena related to momentum, value, profitability, and institutional ownership.

The main and only economically significant difference between the pooled-WLS and RCM-mean VAR estimates is the general persistence of the system. The pooled-WLS estimates imply that the maximum absolute eigenvalue of the VAR transition matrix is equal to 0.915 , whereas the corresponding figure for the RCM-mean estimates is 0.791. On the one hand, the pooled-WLS estimates are likely to overstate the persistence of the system, if the unconditional means vary across firms. The pooled-WLS misinterprets this variation in unconditional means as very persistent transitory variation, thus increasing the persistence of the estimated system. ${ }^{4}$ On the other hand, the RCM-mean estimate is likely to understate the 
system persistence for a typical firm. Because the normality assumption in equation (7) is probably violated by the fat tails of stock-return distributions, the RCM procedure misinterprets some extreme realizations as highly informative about the firm-specific means. ${ }^{5}$ As a consequence, the overall system persistence is likely to be understated.

\section{E. Estimated responses of price and institutional ownership to cash-flow news}

Panel A of Table IV shows the variance decomposition of unexpected returns computed using the following formulas and the VAR model in Panel A of Table III:

$$
\begin{aligned}
\operatorname{var}\left(\tilde{N}_{r}\right) & =\lambda \Sigma \lambda \\
\operatorname{var}\left(\widetilde{N}_{c f}\right) & =\left(e 1^{\prime}+\lambda^{\prime}\right) \Sigma(e 1+\lambda) \\
\operatorname{cov}\left(\widetilde{N}_{r}, \widetilde{N}_{c f}\right) & =\lambda \Sigma(e 1+\lambda)
\end{aligned}
$$

Consistent with Vuolteenaho's (2002) results, cash-flow news is the main driver of market-adjusted firmlevel stock returns. The expected-return-news standard deviation is 25 percent (variance 0.0619 with 0.0208 standard error) and the cash-flow-news standard deviation is 47 percent (variance 0.2182 with 0.0379 standard error). The correlation between the two news series is 0.77 and more than ten standard errors from zero (under the assumption that the VAR model is correctly specified.) Interestingly, the shock to institutional ownership is positively correlated with both cash-flow news (correlation 0.38 ) and expectedreturn news (correlation 0.49). That is, when long-horizon expected returns and cash flows increase, institutions buy shares from individuals.

The RCM results in Table V show the cross-sectional distribution of the variance decompositions. Estimated expected-return-news standard deviations range from 14 percent $\left(5^{\text {th }}\right.$ percentile) to 21 percent $\left(95^{\text {th }}\right.$ percentile), while estimated cash-flow-news standard deviations range from 32 percent $\left(5^{\text {th }}\right.$ percentile) to 95 percent $\left(95^{\text {th }}\right.$ percentile). For the entire $5^{\text {th }}-95^{\text {th }}$ percentile interval, all three pair-wise correlations of expected-return news, cash-flow news, and institution-ownership shock are positive.

Panel B of Table IV shows the estimated regression coefficient of stock return on cash-flow news computed from the pooled-WLS VAR-parameter estimates. The estimated regression coefficient, 0.589, indicates how many cents the price moves on average if there is $\$ 1$ cash-flow news. As discussed in Section I.B, our interpretation of this regression coefficient is that the market underreacts to $\$ 1$ cash-flow news by 41 cents. Since our pooled-WLS estimation method weighs all stocks roughly equally, these underreaction results are best interpreted as applying to a typical small or medium-capitalization stock. 
The RCM-based underreaction estimates are somewhat closer to 1 than the pooled-WLS results, but still systematically below unity. The median estimate is 0.807 , suggesting a perhaps more reasonable 19 cent underreaction to $\$ 1$ cash flow news. Although the median RCM estimate is higher than the pooledWLS estimate, the bulk of the cross-sectional distribution of regression coefficients resides below unity: Estimated regression coefficients of return on cash-flow news range from $0.656\left(5^{\text {th }}\right.$ percentile) to 0.811 ( $95^{\text {th }}$ percentile). According to these RCM estimates, it is fair to say that not only the average stock's price underreacts but most stocks' prices underreact to cash-flow news.

Figure 2 further illustrates some of the dynamics implied by the estimated VAR. The top graph of Figure 2 shows the cumulative response of returns to 25 percent cash-flow news. If expected returns were constant, this shock would result in exactly 25 percent realized unexpected return. Instead, the initial response is only 15 percent, consistent with the above-documented underreaction phenomenon. A notable feature of the impulse-response function is the absence of any delayed overreaction: Instead of overshooting, the price slowly converges to the new level. The bottom graph of Figure 2 also shows the cumulative response of returns to a 25 percent return in the absence of any cash-flow news. After the shock, the price decays for a decade, eventually reversing the entire 25 percent return. These impulse-response functions are largely consistent with those estimated by Vuolteenaho (2002) from a longer 1954-1996 sample.

Chan, Jegadeesh, and Lakonishok (1996) examine the return-predictive power of orthogonalized versions of past returns and earnings "surprises" (SUE) and find that both predict returns with a positive sign. We find that after controlling for the cash-flow news, recent stock returns predict returns with a negative sign. These two results can be reconciled by comparing the methodologies. Chan, Jegadeesh, and Lakonishok's (1996) Table VI Panel B shows that, controlling for SUE, stocks with high past stock returns earn higher stock returns than stocks with low past returns. Since the stock return retains its predictive power after controlling for the most recent SUE, it is tempting to conclude from their Table VI Panel B that return momentum has positive stock return predictive power that is completely independent of cash-flow news. However, such reasoning implicitly assumes that the SUE is a perfect proxy for all new information about all future cash flows. Since past stock returns have incremental forecasting power with respect to future SUEs in the U.S. data (see e.g., Bernard and Thomas $(1989,1990)$ and Chan, Jegadeesh, and Lakonishok's Table VI Panel A), this implicit assumption is clearly false. 
Our VAR methodology enables us to resolve this conundrum: We use the VAR model to compute a measure of cash-flow news that better captures all new information about all future cash flows, including that embedded in stock returns. Using the VAR cash-flow-news measure strengthens the conclusion that past positive cash-flow news is followed by strong future stock returns, controlling for the past stock return. More importantly, when the VAR cash-flow news is used as the cash-flow proxy, the cash-flow proxy drives the marginal relation between past one-year stock return and future one-year stock return from positive to negative. The VAR approach is thus necessary to fully disentangle the predictive power of stock returns and cash-flow shocks.

The lower overall persistence of the RCM-based VAR systems (relative to systems estimated with pooled WLS) translates to faster convergence of the price-response functions. Figure 3 plots median impulse-response function, as well as $10^{\text {th }}$ and $90^{\text {th }}$ percentiles, computed from the firm-specific RCM VAR estimates. We produce the graph by first computing the impulse-response functions for each firm, and then taking the median and percentiles point-wise at each horizon. While the pooled-WLS VAR system needs approximately ten years to incorporate the cash-flow news in the price, the median RCM-based impulseresponse function needs only approximately five years. Although the timing and magnitude of the underreaction is less extreme for RCM-based systems, the general price-reaction patterns are similar to those obtained from systems estimated with pooled WLS.

In addition to documenting the above underreaction pattern, we examine how the ownership structure responds to cash-flow news and high subsequent expected returns. Panel B of Table IV also shows the estimated regression coefficient of institutional-ownership shock on cash-flow news, 0.082 . This regression coefficient shows how large a fraction of the firm institutions buy on average if there is 100 percent cashflow news. Since the regression coefficient is reliably positive (t-statistic 8.9), we conclude that institutions buy on positive cash-flow news. The magnitude of the coefficient is economically significant: onestandard-error cash-flow news results in 4 percent of the firm changing hands between the aggregate groups of individuals and institutions. Firm-specific RCM estimates in Table V are very close to the pooled-WLS estimate in Table IV: Estimated firm-specific regression coefficients of institutional-ownership shock on cash-flow news range from $0.075\left(5^{\text {th }}\right.$ percentile $)$ to 0.089 ( $95^{\text {th }}$ percentile $)$.

Analogously to Figure 2, Figure 4 illustrates the trading dynamics implied by the pooled-WLS VAR. Instead of price response, Figure 4 measures the response of institutional-ownership fraction to shocks. The 
top graph of Figure 4 shows the response of institutional ownership to 25 percent cash-flow news. Contemporaneously with the cash-flow news, institutions buy over 2 percent of the firm and continue to overweight it for several years. The RCM-based estimates in Figure 5 confirm the conclusions drawn from the pooled-WLS results.

The above finding that institutions buy on good and sell on bad cash-flow news is consistent with the institutions following a simple price-momentum strategy. However, the bottom graphs of Figure 4 and Figure 5 show that this is unlikely to be the case. In these two bottom graphs, we shock the VARs with a 25 percent positive return in the absence of any cash-flow news, and record the response of institutional ownership. During such price run-ups that are unrelated to cash-flow news, institutions sell shares to individuals and underweight the stock in their portfolios for years. This effect, too, is economically significant. According to the pooled-WLS VAR of Table III Panel A, the standard deviation of expectedreturn news that is not explained by cash-flow news is approximately 16 percent and one-standard-error move in this residual on average coincides with individuals and institutions changing their aggregate positions by 3 percent of the shares outstanding. The firm-specific estimates again confirm these results. The bottom graph of Figure 5 shows that the entire $10^{\text {th }}-90^{\text {th }}$ percentile spectrum of estimates is consistent with institutions selling contemporaneously with price increases that are unrelated to cash-flow news.

We also measure the extent to which the patterns in institutional portfolio allocations coincide with the patterns in expected returns. To examine whether institutions in aggregate take positions proportional to expected returns, we compute the correlation between short- and long-term expected returns and the level of institutional ownership. The one-period expected return is computed simply as the fitted value from the first VAR prediction equation. The measure of long-horizon expected return we adopt is the "atypical discount," $p_{r}$, as defined by Vuolteenaho (2002):

$$
p_{r, t-1} \equiv \sum_{j=0}^{\infty} \rho^{j}\left(E_{t-1} r_{t+j}-\bar{r}\right)
$$

Above, $\bar{r} \equiv E(r)$ denotes the normal or typical log risk premium. ${ }^{6}$ As seen from equation (10), atypical discount is the cumulative effect of return predictability on prices. If a stock's atypical discount is high, the expected future returns on this stock are also high and the stock price is low (relative to the expected cash flows). The market-adjusted atypical discount, $\widetilde{p}_{r, t-1} \equiv \sum_{j=0}^{\infty} \rho^{j} E_{t-1} \widetilde{r}_{t+j}$, can be conveniently computed 
from the VAR model using the formula $\rho^{-1} \lambda^{\prime}\left(z_{t-1}-\bar{z}\right)$, where $\bar{z}$ denotes the unconditional mean state vector.

Panel C of Table IV shows the pooled-WLS estimates of the covariance and correlation matrices of one-period expected return, long-horizon expected return $\left(\widetilde{p}_{r}\right)$, and the fraction of institutional ownership. The correlation between one-period expected returns and the level of institutional ownership is 0.41 with a 0.06 standard error. The correlation between long-horizon expected returns and the level of institutional ownership is somewhat stronger at 0.64 with a 0.09 standard error. If one were to assign the causality from long-horizon expected returns to institutional ownership and regress the ownership fraction on long-horizon expected returns, this regression would explain 41 percent of the variation in institutional ownership.

The RCM-based estimates of correlation between expected returns and institutional ownership are somewhat lower. Table V shows that the firm-specific estimates of the correlation between institutional ownership and one-year abnormal expected returns range from $0.13\left(5^{\text {th }}\right.$ percentile) to 0.57 percent $\left(95^{\text {th }}\right.$ percentile). The estimated correlations of long-horizon expected returns $\left(\widetilde{p}_{r, i}\right)$ and institutional ownership are less disperse: $5^{\text {th }}$ percentile at 0.26 , median at 0.29 , and $95^{\text {th }}$ percentile at 0.33 .

\section{F. Size patterns in underreaction and trading}

Previous research shows that the underreaction pattern varies as a function of the firm's characteristics. We first measure this size pattern in underreaction and then contrast it to the pattern in trading between individuals and institutions.

One way to allow for cross-sectional variation in the underreaction pattern is to let the VAR-error covariance matrix $\Sigma$ vary across firms while assuming that the VAR coefficient matrix $\Gamma$ is common for all stocks. In Table VI Panel A and Figure 6 (top two graphs), we sort stocks into quintiles based on firm size (i.e., market value of equity) and estimate a separate underreaction coefficient for each group. In this sample, the regression coefficient of return on cash-flow news varies as a function of firm size. For the smallest quintile of stocks in our sample, the coefficient is 0.55 , corresponding to a 45 -cent underreaction to one-dollar cash-flow news. For the largest stocks, the regressions coefficient is significantly higher: 0.67 or 33-cent underreaction to one-dollar cash-flow news. The difference in coefficients between the two extreme quintiles is 0.10 , two-and-half standard errors from zero.

Because we constrain the transition matrix to be equal across size groups, the size-related heterogeneity in the underreaction pattern might be an artifact of this restriction. To investigate this 
possibility, we estimate a separate transition matrix for each size quintile and assume that each firm's assignment to a size quintile is permanent. ${ }^{7}$ The results obtained under these assumptions (presented in Table VI Panel B and Figure 6 (bottom two graphs)) show an even stronger size pattern in underreaction. As above, the stocks in the smallest quintile have a return-on-cash-flow-news coefficient of 0.56 , corresponding to a 44-cent underreaction to one-dollar cash-flow news. For the largest stocks, allowing the transition matrix to vary as a function of size changes the results significantly: the estimated coefficient is 1.01 , or almost exactly correct reaction to cash-flow news. The difference in coefficients between the two extreme quintiles is -0.45 , almost four standard errors from zero. These estimates are consistent with our prior of the dispersion in expected returns within the large-capitalization universe being minimal.

Also the regression coefficient of institutional-ownership shock on cash-flow news varies as a function of firm size. In Table VI Panel A, stocks in all quintiles are assumed to share the same transition matrix, but the error covariance matrix is allowed to vary across the quintiles. For the smallest quintile, the coefficient is 0.0455 , and for the largest quintile 0.1375 . The difference in coefficients between the two extreme quintiles is -0.0920 with a 0.0139 standard error. Table VI Panel B uses slightly different assumptions: We assume that the size-group assignment is permanent and estimate a separate transition matrix and error covariance matrix for stocks in each size quintile. The point estimates have a lower precision but are generally consistent with the above-mentioned results obtained under different assumptions.

\section{G. Is bad news different from good news?}

Hong, Lim, and Stein (2000) show that momentum profits are concentrated in the continuation of recent losers' returns. Hong, Lim, and Stein suggest that "to the extent that stock prices do underreact, they are more prone to underreact to bad news than to good news." To examine this possibility, we first compute the fitted values of cash-flow news using the VAR model of Table III Panel A. We then regress stock returns and institutional-ownership shock on a constant, cash-flow news, and the minimum of cashflow news and zero. The results in Table VII confirm the conclusions of Hong, Lim, and Stein. For a typical stock, the average price reaction to one-dollar positive cash-flow news is 66 cents, while the average price reaction to one-dollar negative cash-flow news is 55 cents. In addition to the expected patterns in price responses, we also find that institutional ownership responds asymmetrically to cash-flow news. The 
regression coefficient of institutional-ownership shock on cash-flow news is 0.1038 for good news, but only 0.0724 for bad news.

We also estimate the asymmetric-response model for size quintiles. As in Table VI, we compute cash-flow news under two different assumptions. Panel B of Table VII assumes that all size quintiles share the same transition matrix $\Gamma$ in estimation of the cash-flow-news terms. Panel $\mathrm{C}$ of Table VII uses cashflow news estimated under the assumptions that stocks in different size quintiles have different transition matrices and that a stock's quintile assignment is permanent. Irrespective of the specific assumptions, the following patterns emerge. First, the asymmetry in price responses is much larger for small than for large stocks. This finding is consistent with that of Hong, Lim, and Stein (2000), who also argue that small stocks react especially sluggishly to bad news. Second, the institutional holdings respond more strongly to bad news for large stocks than for small stocks. For the largest stocks, institutional holdings actually respond with a higher coefficient to bad news than to good news.

These asymmetric-response results come with a caveat. Our methodology assumes that the predictive coefficients of the VAR state variables are symmetric, i.e., we do not allow for nonlinearities or kinks in the conditional expectation function. In practice this means that, for example, the predictive coefficient of returns on past returns is the same for negative and positive past returns. Therefore, we interpret these results only as a robustness check, which verifies that our estimated news terms do not behave in a manner inconsistent with previous research. A more complete treatment of these asymmetries would require a more complicated nonlinear or piece-wise-linear time-series model.

\section{H. Further evidence on reversals of momentum profits}

Grinblatt, Titman and Wermers (1995) and Jegadeesh and Titman (2001) find, respectively, that mutual funds buy high momentum stocks, and that, while momentum stocks have high short-horizon returns, these momentum profits are eventually reversed. Our results that institutional investors buy momentum stocks is broadly consistent with Grinblatt, Titman and Wermers's (1995) findings. However, our results may first appear inconsistent with Jegadeesh and Titman's (2001) result that the momentum profits eventually reverse.

Heterogeneity of momentum stocks allows us to reconcile our results with Grinblatt, Titman and Wermers's (1995) and Jegadeesh and Titman's (2001). Although institutions buy some momentum stocks

and momentum profits earned by the average momentum stock reverse, the momentum profits on the 
momentum stocks bought by institutions do not reverse. Figure 7 illustrates this heterogeneity of momentum stocks with our VAR model. The top panel plots the price response to the event of a $25 \%$ return and a one-standard-deviation positive shock to institutional ownership. The bottom panel plots the price response to the event of a $25 \%$ return and a one-standard-deviation negative shock to institutional ownership. Both experiments lead to short-run momentum profits. However, the difference between the top and bottom panels is striking for horizons beyond one year. Clearly, the momentum profits on the stocks bought by institutions do not reverse; instead they appear to slightly increase after the one-year horizon. The momentum profits following a $25 \%$ return and institutional selling are slightly positive during the first year but strongly reverse after the one-year horizon. Unreported experiments with out-of-sample portfolio returns support these conclusions and suggest that the above results are not an artifact of the imposed VAR structure.

We interpret Figure 7 as evidence supporting our general conclusions that institutions are better able to discriminate between stock price movements that are justified and those that are unjustified by cash-flow fundamentals.

\section{Discussion}

\section{A. How aggressively do institutions trade on cash-flow news?}

The existence of the stock-price underreaction phenomenon implies that the price effects of some investors' underreaction are not "arbitraged away." In particular, the institutions are not buying enough stock in response to good cash-flow news to offset the selling by individuals.

The fact that institutional trading does not completely eliminate the underreaction phenomenon should not be a surprise, even if the institutions are not subject to any behavioral biases or exogenous constraints. In a market populated by other rational mean-variance optimizers, a mean-variance optimizer would follow the dictates of the CAPM and maximize diversification by holding each asset in proportion to its market capitalization. If such an investor becomes aware that the market is underpricing certain stocks, the investor will recognize a benefit from shifting their wealth toward these assets.

However, a mean-variance optimizer will not keep buying the underpriced assets until those assets are no longer underpriced, because of the lost-diversification cost. In particular, if institutions bought a stock until it is only underpriced by a small amount, purchasing more of the stock would lead to a first-order 
loss in diversification with only a second-order gain in expected returns. Clearly, a mean-variance optimizing institution overweights a stock subsequent to positive cash-flow news but not enough to completely offset the underweighting by individuals.

Do institutions as a group exploit the underreaction pattern as aggressively as a mean-variance optimizer would? We test whether the aggregate institutional portfolio is mean-variance efficient using the Black-Jensen-Scholes (1972) test. For simplicity, we use a single test asset: a managed portfolio that is long positive-cash-flow-news stocks and short negative-cash-flow-news stocks. The return on this test asset is regressed on the aggregate institutional return less the risk-free rate. We find that the intercept of this regression is positive and thus reject the mean-variance efficiency of the institutional portfolio. Furthermore, the positive intercept indicates that the institutions as a group should trade more aggressively on news to reach the mean-variance optimum.

Table VIII shows the details of this test. We form our test-asset portfolio using the following procedure. On June 30 of year $t$, we estimate a VAR model from past data and compute the calendar year $t$ 1 cash-flow news for each stock. The VAR includes log return, profitability, and book-to-market as state variables, and the data begin in 1954. Then, we set the portfolio weight for each stock equal to the year $t-1$ cash-flow news. Since the market-adjusted cash-flow-news terms have zero mean in each cross-section, the sum of the portfolio weights will be zero. (The sum of long weights is normalized to unity.) We compute monthly returns for this cash-flow-news portfolio from July 1 to June 30 of the next year $(t+1)$ and rebalance the weights every month. This cash-flow-news portfolio return spans the period 7/81-12/98. The mean monthly return of this long-short portfolio is 0.74 percent, and the monthly return standard deviation is 3.83 percent. The monthly Sharpe ratio is 0.19 , which is close to that of the market over the same period (0.19) and somewhat higher than that for the market over the 1926-99 period (0.13). We can reject the hypothesis that the mean return is zero with a t-statistic of 2.79. Regressed against the excess market return, this portfolio return has an alpha of 0.75 percent per month (t-statistic 2.78 ) and a beta of -0.014 (t-statistic -0.22). Consistent with other underreaction findings, the CAPM cannot price this portfolio return.

Next, we regress the return of the cash-flow-news portfolio on the excess return of aggregate institutional portfolio. The results are similar to those for the market: alpha of 0.74 percent with a $2.74 \mathrm{t}$ statistic; beta of -0.00 (t-statistic -0.01). We reject the hypothesis that the aggregate institutional portfolio is 
mean-variance efficient. Moreover, the positive sign on the intercept indicates that the inefficiency results from institutions exploiting the underreaction too little, rather than too much (Treynor and Black (1973)).

Table VIII Panel $\mathrm{C}$ explores the actual portfolio allocations of institutions and individuals by regressing the institutional holdings on the CRSP value-weight portfolio less T-bill and the cash-flow-news portfolio. These regressions indicate that the institutions have approximate 104 percent weight in the market and approximately 2 percent (t-statistic 3.17 ) weight in the cash-flow-news portfolio. In contrast, individuals appear to be 96 percent in the market and -2 percent (t-statistic -1.97 ) in the cash-flow-news portfolio. We also disaggregate institutional holdings into five groups: banks, insurance companies, mutual funds, investment advisors, and other institutions. Of these groups, banks appear to have performed the best during this sample period, delivering a mean return of 0.89 percent per month and a Sharpe ratio of 0.21. Our results suggest that none of the institutional-investor groups is mean-variance efficient, with Panel B alphas above 0.73 percent and t-statistics above 2.7. The portfolio allocations in the cash-flow-news portfolio range from 3 percent by banks to 1 percent by investment advisors.

Simple calculations show that the in-sample mean-variance optimal portfolio has approximately half the weight in each of the long-short portfolio and the aggregate institutional portfolio. Thus while the institutions are tilting their portfolio into right direction, this 2 percent weight is far from the in-sample optimum.

An alternative way to illustrate the conservative nature of the institutional portfolio allocations is to ask Should institutions do more of what they are currently doing? Consider an investor who holds $\$ 1$ in the CRSP value-weight portfolio and can costlessly invest in a hedge fund that holds a portfolio that is the difference between the aggregate institutional portfolio and the CRSP value-weight portfolio. Investing \$1 in this hedge fund will recover the aggregate institutional portfolio. The optimum that maximizes the insample Sharpe ratio is, however, much higher at \$7.54. In other words, if our sample is representative of the population, mean-variance optimization would dictate institutions deviating 7.5 times more aggressively from the value-weight index than they currently do.

These findings suggests that, given the prices, institutions are being far too conservative in deviating from the value-weight market index in general, and in exploiting the underreaction phenomenon in particular. As a result, although institutions are trading in the right direction, institutions as a group 
outperform individuals by only 1.44 percent per annum. This comparison assumes that neither institutions nor individuals incur any transaction or other costs.

\section{B. Why do institutions not trade more aggressively?}

We find that institutions are making profitable trades but are not aggressive enough as a group to cause their aggregate portfolio to be mean-variance efficient. There are several possible explanations for this behavior. One explanation is that institutions may simply make the same types of errors as the households in underreacting to cash-flow news, but make these errors to a lesser degree.

It is also plausible that institutions recognize the opportunity presented by underreaction to cash-flow news, but are unable to take full advantage of it. We follow Shleifer and Vishny (1997) and characterize such hypotheses as "limits of arbitrage." For example, high transaction costs may make it unprofitable to run a small-stock strategy with high turnover. In general, transaction costs are incurred in many forms. Perhaps the most basic of these is information costs. In our case, however, identifying stocks that have had good news about cash flows is fairly simple. Another obvious source of transaction costs is trading costs. Buying and selling (and especially short selling) stocks can be costly, in particular in the case of small stocks where price impact and share-lending costs can be important issues. Nevertheless, in our opinion, the expected-return differentials are sufficiently large that trading costs are unlikely to completely outweigh them, at least for a single small fund.

In addition to costs-based constraints, fund managers often limit their potential holdings by written and unwritten rules. One of the most important written rules is the "Prudent Man Rule," which states that a fiduciary must invest fund assets as a prudent man would. The interpretation of the rule has in recent decades come to be that the fund as a whole must be prudently invested, rather than each individual asset held by the fund. Nevertheless, many institutions may perceive that holding small, distressed, and/or nondividend-paying stocks puts them at risk of being judged "imprudent" if fund performance is poor.

Another concern of institutional investors is tracking-error volatility, the typical amount by which the return on the institution's portfolio deviates from the return on a benchmark portfolio. Explicit or implicit tracking-error constraints; perhaps for marketing strategy, risk management, or agency cost reasons; may considerably limit the ability of many institutions to aggressively pursue investment strategies such as the cash-flow-news strategy we describe. ${ }^{8}$ 
The hypothesis that institutional portfolio managers trade off Sharpe ratio and tracking error appears consistent with our results: Institutions trade in the correct direction, but not very aggressively. Figure 8 shows the estimated trade-off between expected return and tracking error. The dotted line in Figure 8 is the portfolio opportunity set generated by combining the CRSP VW market portfolio and a portfolio with weights equal to the difference between the aggregate institutional portfolio and the CRSP VW market portfolio. Investing one dollar in the CRSP VW market portfolio and one dollar in this difference portfolio recovers the aggregate institutional portfolio (denoted by a circle on the solid line). Currently, the aggregate institutional portfolio has approximately a 1.6 percent tracking-error standard deviation.

The dotted line combines the CRSP VW portfolio and the cash-flow-news portfolio from Table VIII, i.e., a portfolio that goes long in stocks that have experienced positive cash-flow news during the previous year and goes short in stocks that have experienced negative cash-flow news during the previous year. Without any short-sale constraints or constraints on trading small stocks, this strategy would have produced a mean excess return of approximately 1.1 percent if tracking-error standard deviation had been set to 1.6 percent.

Many institutional clients of professional money managers impose explicit tracking-error limits on the managers. These limits appear to be under five percent in typical cases. ${ }^{9}$ In Figure 8, five percent tracking-error volatility corresponds to 3.3 percent outperformance on the solid line and to 2.5 percent outperformance on the dotted line. Despite their ability to pick stocks, it is unreasonable to expect the institutions to massively outperform the benchmark index, either in aggregate or individually, if they can only afford a tracking-error volatility of a couple of percent.

Nevertheless, the relatively high in-sample slopes of the solid and dotted line in Figure 8 may indicate that simple tracking-error concerns are not the whole story. If a fund faces short-sale constraints, the available opportunities may not be as attractive. The curved, dash-dotted line graphs the portfolio opportunity set generated by combining the CRSP VW market portfolio and the difference between the aggregate institutional portfolio and the CRSP VW market portfolio, but constraining the portfolio weights to be positive and thus not allowing short positions. Remarkably, the trade-off between expected return and tracking error levels quickly when the tracking-error volatility approaches 2 percent. The opportunities available from the cash-flow-news strategy also rely on the ability to short. The dashed line shows the trade-off between expected return and tracking error when combining the CRSP VW portfolio and the cash- 
flow news portfolio, but constraining the total weight in any security to be nonnegative. At zero, the solid line and dashed line have the same slope, but the slope of the dashed line declines quickly to approximately 0.27 percent of expected return per one percent of tracking-error volatility. The attenuation of the slope is a clear demonstration of both the underreaction phenomenon and the resulting profit opportunities being concentrated to negative news for small stocks, consistent with our findings in Table VII and Figure 6.

The short-sale constraints may explain why the price reaction to bad cash-flow news appears especially sluggish, as documented in Section I.G. Institutional rigidities and financial regulations may make shorting impossible or undesirable for many institutions. Many institutions simply do not short stocks as a matter of policy or institutional charter. We speculate that the causes for such self-imposed constrains may include associating short selling with risk, a fear that betting against companies will create negative publicity, and/or a limitation placed on managers to alleviate some agency problem associated with the unlimited liability of short positions. Irrespective of the underlying causes, the empirical fact is clear: many financial institutions do little or no short selling. The low institutional selling response to bad news for small stocks, documented in Table VII, is consistent with this hypothesis.

Of course, the trade-off between expected return and tracking-error volatility in the presence of shortsale constraints deserves a much more detailed examination with a proper statistical analysis. Nevertheless, we would like to bring up these hypotheses as possible explanations, and hope to explore this issue at individual institution level in future research.

The above hypotheses consider institutions a monolithic group in their beliefs and preferences. In reality, it seems that a vast array of different institutions exists in the market. It may be that a small, knowledgeable subset of the institutions trade more aggressively and obtain high returns and Sharpe ratios. It is possible that while some institutions recognize the opportunity presented by underreaction to cash-flow news, the majority of institutions behave much like individuals. Since only a small subset of institutions invests in mean-variance efficient portfolios, institutions in the aggregate do not appear aggressive enough.

It is also possible that institutions are heterogeneous in both their ability to invest in and their understanding of various sectors of the stock market. A technology manager may not be allowed to invest in energy stocks nor a value manager in growth stocks. A portfolio manager with a mandate to invest in only a subset of firms may not trade as aggressively as would an unconstrained manager. The managers may also be heterogeneous in their abilities, not only in their investment mandates. For example, a value 
manager may not understand growth stocks' cash-flow processes very well. If this manager nevertheless trades some growth stocks, he/she may commit errors similar to those committed by individuals.

\section{Why are institutions less active in trading small stocks?}

Our results also raise the question why institutional investors do not respond more aggressively to the cash-flow-news underreaction of small stocks, exploiting the larger opportunities. One hypothesis is that many institutions face various constraints in trading small stocks, or that they simply prefer to trade large stocks. This hypothesis is supported by Falkenstein (1996), Gompers and Metrick (2001), and others who find that institutions prefer to hold large, liquid stocks. These authors suggest that the large positions held by institutions may lead them to demand stocks with large market capitalizations and thick markets. For example, if institutions turn over their portfolios and trade more often than individuals do (Schwartz and Shapiro (1992)), then they would be more sensitive to the transactions costs caused by large-percentage bidask spreads for illiquid or low-priced stocks. In addition, many institutions are explicitly or implicitly constrained to only invest in stocks that are heavily weighted in a particular benchmark index, such as the S\&P 500 (Shleifer (1986), Harris and Gurel (1986), Beneish and Whaley (1996), Lynch and Mendenhall (1997), and others). These often self-imposed constraints may stem from various agency considerations.

Finally, costly SEC reporting requirements for investors that hold more than five percent of a firm's stock may lead to some institutional avoidance of small firms.

If institutions indeed face constraints in taking small-stock positions, the institutional trading patterns may offer an explanation to the cross-sectional underreaction patterns. If individuals underreact more than institutions, their underreaction is likely to impact the prices more in markets where institutional trading is constrained, such as small stocks. However, because market value of equity is endogenous and correlated with many other observable and unobservable variables, such conclusion would be speculative.

\section{Reconciling our results with the previous results on net-of-fees performance}

It is also interesting to relate our results to the literature on the investment performance of money managers. Our finding that institutions trade in the right direction, albeit very conservatively, may seem contrary to the conventional wisdom that professional money managers do not deliver superior returns to their clients. Below, we reconcile our results with this widely held view by examining the mutual-fund subset of the Spectrum database. 
We find that in our 1981-1998 period the typical mutual fund in the Spectrum data chose stocks that returned $18.17 \%$ per annum in the absence of fees and transaction costs (the return for all institutions over the same period was almost identical). This exceeded the annual CRSP value-weight market return over the same period (17.36\%) by 81 basis points (b.p.). The net return after fees of a matched set of funds in the CRSP Mutual Fund database was $15.67 \%$, 159 b.p. below the CRSP value-weight market and 250 b.p. below the gross return of the funds. 88 b.p. of these 250 b.p. can be explained by management fees, estimated using Wermers's (2000) methodology. The remainder (162 b.p.) is due to a combination of trading costs and "cash drag," the loss of return due to the fact that liquidity-induced non-stock holdings of funds underperformed stock holdings.

The substantial cost of trading is unsurprising given how much of it funds do. In our sample, mutual funds exhibit $70.6 \%$ annual turnover (value-weight average). This computation is based on the definition of turnover used by CRSP, which is the greater of total purchases or total sales, divided by average fund value. Thus the total value of one-way trades can significantly exceed the given value, up to a factor of two. Using a reasonable one-way trading cost (including price impact) of 75 b.p., we might expect trading costs to eat up perhaps 53-106 b.p. per year for a typical fund; this would leave approximately 56-109 b.p. to be explained by cash drag. These numbers are quite similar to those estimated from a partially overlapping sample and time period by Wermers (2000). According to Wermers, the 1976-1994 value-weight average management fee is 79 b.p., average transaction costs 80 b.p, and cash drag 70 b.p.

\section{E. Risk or mispricing?}

The expected-return patterns detected by our VAR can, in principle, be due to variation in a firm's risk instead of mispricing. A rational model of the underreaction pattern would have to explain two related features of the data: First, a risk-related story for the positive correlation between cash-flow news and expected-return news and, second, a reason why this risk is more efficiently borne by investing through large institutions than via a direct investment by individuals.

Vuolteenaho (2002) provides a simple risk-based story for the positive correlation between expected return news and cash-flow news. Suppose that firms frequently take on new projects, and that firms only consider projects with zero or positive NPV. Further suppose that due to competitive forces in the goods markets, the vast majority of new projects are zero NPV or very close to zero NPV. In such a case almost all new projects will be one of the following types: Type one are risky (high discount rate) projects with 
high cash-flows, and type two are less risky (low discount rate) projects with low expected cash-flows. Projects with low expected cash-flows and high discount rates will not be pursued because they have negative NPV, and projects with high expected cash-flows and low discount rates will tend not to exist because competitive forces will reduce the future expected cash-flows of such projects. As a consequence, announcements of new projects by firms will tend to either alert the market to an increase in both expected cash-flows and expected returns or a decrease in both expected cash-flows and expected returns -- the exact positive correlation of the new series we seek to explain.

To date, there has been relatively little empirical testing of risk-based explanations of earnings momentum and other phenomena related to the positive correlation of cash-flow news and expected-return news. However, some recent studies have found evidence that risk my be associated with some of the related asset pricing anomalies. The high returns of firms with positive cash-flow news are related to both the value and momentum effects; value because good cash-flow news tends to lead to an increase in book value and thus in the book-to-market ratio, and momentum because good cash-flow news is also associated with high contemporaneous returns. Lettau and Ludvigson (2001) propose a risk-based model that has some success in pricing the book-to-market effect. Pastor and Stambaugh (2001) argue that risks related to liquidity may help explain why past returns predict future returns. Ang and Chen (2001) present evidence that momentum stocks may perform poorly in down markets to an even greater extent than predicted by their betas, thus helping to explain the high expected returns on such stocks as risk-based. While all of these results are preliminary and apply only indirectly, they suggest that a risk-based explanation for the high expected returns of positive cash-flow news stocks is possible.

Why would institutions tend to be the purchasers of stocks whose expected returns (and risk) have recently increased? One category of explanations is based on the notion that institutions are merely an intermediary through which individuals hold securities. There are many possible reasons why individuals might choose to hold their riskier stocks in institutions and their less risky stocks in their personal accounts. Efficient holding of riskier stocks may require implementation of dynamic trading strategies, which are costlier for individuals than for institutions. Individuals may tend to use their holdings in pension funds, 401(k) plans, insurance pools, and perhaps even mutual funds as the proper home for their long-term investments. Legal barriers to the removal of funds from such institutions, including tax penalties for doing so, could help to enforce such an equilibrium. When a stock's risk and expected return increase, there will 
be a rational tendency for individuals with a short horizon to sell those stocks to institutions, who recognize their role as holding long-term investments on behalf of their investors.

\section{Additional robustness checks}

\section{A. Potential errors-in-variables problems}

A potential concern with our underreaction measure is the attenuation bias arising from the errors-invariables problem. Because we estimate the cash-flow-news terms, they are contaminated with sampling error. If this sampling error is independent of the true cash-flow news and returns, the regression coefficient of returns on estimated cash-flow news is biased towards zero.

Below, we provide four different robustness checks to show that when this regression is implemented with Campbell's (1991) return decomposition, it is immune to the attenuation bias. Our intuition is that the bias is negligible because the sampling error in the estimated cash-flow-news terms is not independent of the stock return. In effect, Campbell's (1991) VAR return-decomposition methodology gives the benefit of the doubt to cash-flow news: The VAR allocates the entire return to cash-flow news unless it finds evidence of the return reversing.

First, we estimate the bias in our underreaction-coefficient estimator using the jackknife. (Efron (1982) reviews jackknife bias estimation.) In summary, the attenuation bias turns out to be negligible. For example, the jackknife bias estimate for the underreaction coefficient in Panel B of Table IV is -0.0035 , which is economically insignificant relative to the point estimate of 0.5893 .

Second, we produce artificial data for the VAR by subtracting some fraction of the conditional expected returns from the returns. We vary this fraction over the interval 0 to 1.5 , which spans the case of perfectly unpredictable returns (at 1.0). For each fraction, we measure the population underreaction coefficient and create new bootstrap samples by drawing whole cross sections of $x-y$ pairs. Then, we compute the mean underreaction coefficient obtained from the bootstrap samples and compare it to the population underreaction coefficient. Over the entire [0,1.5] range, the maximum downward bias in the underreaction coefficient is 0.0166 , which is both economically and statistically negligible.

Third, we added transitory noise to the explanatory variables other than past stock return to explore the sensitivity of our methodology to model misspecification. For all noise levels we tried, the 
underreaction coefficient regressed towards one, not zero. This experiment suggests that our underreactioncoefficient estimate is likely to be biased towards not finding underreaction, if our VAR is misspecified.

Fourth, we run an out-of-sample predictive test to see whether the out-of-sample return-prediction performance is consistent with the impulse-response functions in the top panels of Figures 2 and 3. We use the out-of-sample portfolio strategy from Table VIII, the Ncf portfolio. The difference between the Ncf portfolio's long and short components' past cash-flow news is on average $100 \%$. The magnitude of the average returns on the Ncf portfolio is consistent with the expected price path in the top panels of Figures 2 and 3: The Ncf portfolio earns $12 \%$ during the first year and $25 \%$ cumulatively over four years subsequent to portfolio formation.

\section{B. Potential selection biases and the influence of delisting events}

Since we do not impose any restrictions on the dependent variables in the VAR estimation, our results are unlikely to be significantly influenced by selection biases. Under the assumptions that the population data are generated by the VAR and that the probability of a firm-year being included in the sample depends only on the lagged values of the state variables, the VAR parameters are estimated consistently if we do not impose any data requirements on the dependent variables of our regressions.

Of course, it is possible that the data-generating process changes when a firm is dropped from our sample. For example, a merger or delisting is likely to affect the VAR transition matrix. Since unobserved data are by definition not observable, we can only perform back-of-the-envelope robustness checks to control for this possibility. As such a robustness check, we take the estimated cash-flow-news terms from the VAR in Table III Panel A and regress returns and institutional-ownership shock on a constant, estimated cash-flow news, and a dummy variable. The dummy variable takes the value one if the firm disappears from the sample during the year and zero otherwise. This regression and other similar experiments (e.g., including an interaction term) show that controlling for events that cause a firm to disappear from the sample does not change any of our stated results. Of course, this conclusion is conditional on the cash-flownews terms being estimated correctly by the VAR model in Table III Panel A.

\section{Expected simple returns and directly computed cash-flow news}

Variation in expected log returns does not necessarily imply variation in expected simple returns. For example, if log returns are conditionally normal, the conditional expected simple return equals 


$$
E_{t-1}\left(1+R_{t}\right)=\exp \left[E_{t-1}\left(\log \left(1+R_{t}\right)\right)+\frac{1}{2} \operatorname{var}_{t-1}\left(\log \left(1+R_{t}\right)\right)\right]
$$

Hence, expected log return may change simply because the conditional log-return variance changes. Another related concern is the size of the approximation error embedded into the cash-flow-news term in indirect computation of cash-flow news. To jointly examine these two issues, we estimate a VAR specification with simple instead of log returns and add the clean-surplus ROE to the state vector. This VAR enables us to examine the response of expected simple returns to directly computed cash-flow news. Figure 9 shows the responses of expected simple returns and institutional ownership to directly computed cash-flow news and illustrates that our results are not artifacts of either Jensen's inequality or the approximation error.

\section{Alternative VAR specifications}

Our first-order VAR model is obviously a gross simplification of reality. While it is impossible to unambiguously verify that our results are not artifacts of a specification error, we can show that some other reasonable VAR specifications yield essentially the same results.

Table IX confirms our basic results by showing estimates obtained from richer VAR specifications.

The set of predictive variables include five lags of past stock returns, two lags of profitability, two lags of institutional ownership, two lags of the book-to-market ratio, two lags of leverage, and one lag of standardized log market equity. The qualitative results obtained from these more elaborate specifications are similar to the main results obtained from our simple VAR in Panel A of Table III. Across specifications, the regression coefficients of return and institutional-ownership shock on cash-flow news are approximately 0.5 and 0.05. Due to the additional free parameters, the standard errors of these estimates are somewhat larger at approximately 0.1 and 0.01 . Generally, our qualitative results do not appear to be sensitive to the lag order, and many other elaborate specifications give similar results.

\section{Conclusions}

Prior research has documented the tendency of stock prices to underreact to news about cash flows, especially to bad news about small stocks. To further investigate this underreaction phenomenon, we analyze the dynamics of returns, cash-flow news, and trading between individual and institutional investors using a vector autoregression (VAR) and data on individual stocks. Although our VAR is undoubtedly a 
gross simplification of reality, we hope that it is a useful way to think about the links between institutional trading, prices, and expected cash flows.

Our main finding is that in response to positive cash-flow news and subsequent high expected returns, institutions in the aggregate buy shares from individuals, thus exploiting the underreaction phenomenon. The effect is economically significant: Institutions, which hold on average 36 percent of a typical stock, buy an additional 4 percent of the outstanding shares in response to a one-standard-deviation shock to expected future cash flows. The institutions are not simply following price-momentum strategies (or following mechanical market-capitalization rules and thereby buying larger stocks and selling smaller): When a stock's price increases 25 percent without any concomitant cash-flow news, institutions sell 5 percent of the outstanding shares to individuals. Our main results are robust to a number of methodological variations.

We offer two different interpretations of our results. On the one hand, if one assumes that the underreaction pattern in prices is due to investor irrationality, individuals appear to be the main culprits. They buy stocks during price run-ups that are unrelated to cash-flow fundamentals and do not appear to adjust their demand curves for shares sufficiently in response to new cash-flow information.

Our results are largely consistent with institutions truly understanding the return-generating process and using this understanding to make smart bets. However, our findings are also consistent with institutions following rules of thumb motivated by some completely unrelated factors, and these rules of thumb being positively correlated with expected returns. To some extent, this distinction is moot. As argued by Milton Friedman (1953), while modeling a skilled pool player as literally calculating exactly how hard and at what angle to hit the ball is certainly an unrealistic description of reality, such a model may be a very good predictor of much more complicated reality and thus a useful way to think about a skilled pool player. Similarly, the exact mechanism of institutional investment decision making may be based on a complicated set of heuristics, yet it may be adequately modeled as rational-expectations maximization.

On the other hand, one may assume rational expectations for both institutions and individuals and that the positive cash-flow news is followed by high expected returns because positive cash-flow news coincides with an increase in risk. Such an increase in risk would be somewhat counterintuitive, as the typical distress or leverage intuition would suggest that good cash-flow news coincide with a decrease in risk. Nevertheless, based on our analysis alone, one cannot rule out the possibility of risk as an explanation 
for the high expected returns subsequent to positive cash-flow news. Since this increase in risk induces selling by individuals to institutions, this (yet unidentified) risk must be of especially significant concern to individual investors.

If the underreaction phenomenon is due to investor irrationality, why does the institutional trading not eliminate the underreaction? Since the strategy the institutions are following requires sacrificing diversification by overweighting the stocks with recent positive cash-flow news, it would not be in the interest of institutions to buy until the stocks are no longer mispriced. Rather, there is an optimal amount of buying that will lead to an efficient portfolio. We test the aggregate institutional portfolio and find that it is not mean-variance efficient. The institutions as a group are much less aggressive in buying positive-cashflow-news stocks and selling negative-cash-flow-news stocks than a rational mean-variance optimizer would be.

We speculate that the conservative behavior of institutions as a group may be due to constraints on the investment universe (such as only investing in large-capitalization stocks), tracking-error concerns, and reluctance to short stocks. These constraints may also cast light on the cross-sectional underreaction patterns. The institutions hold and actively trade large-capitalization stocks; large-capitalization stocks show virtually no underreaction pattern. The institutional selling response to bad cash-flow news is weakest among small stocks; small stocks also show the strongest underreaction patterns, especially to bad news. These findings are consistent with institutions facing exogenous constraints in trading small stocks in general and in shorting them in particular.

Our results are inconsistent with the hypothesis that institutional investors follow positive-feedback investment strategies (Lakonishok, Shleifer, and Vishny (1992a) and others). According to our results, institutional investors follow cash-flow-momentum strategies, but are contrarian relative to price movements that are unrelated to cash flows. If cash-flow news is exogenous, such institutional buying cannot feed back to cause more institutional buying. Also, because the institutions do not appear to "jump in" during "price rallies" that are not justified by cash-flow fundamentals, it is difficult to classify institutions as either the noise traders or the sophisticated investors in the destabilizing-speculation model of DeLong, Shleifer, Summers, and Waldmann (1990). 
At minimum, our results suggest that future empirical studies investigating investors' trading behavior, or testing herding or positive-feedback-trading theories, should carefully separate the effects of cash-flow momentum and price momentum. 


\section{Appendix 1: Approximate present-value model}

Three main assumptions are made to derive the ROE-based version of the approximate present-value model of Vuolteenaho (2001). First, book equity $(B)$, dividend $(D)$, and market equity $(M)$ are assumed to be strictly positive. Second, the difference between log book equity $(b)$ and log market equity $(m)$ and the difference between log dividend $(d)$ and log book equity are assumed to be stationary, even though the series individually have an integrated component. Third, earnings $(X)$, dividends, and book equity must satisfy the clean-surplus identity:

$$
B_{t}=B_{t-1}+X_{t}-D_{t}
$$

- book equity this year equals book equity last year plus earnings less dividends.

Market and accounting returns (i.e., ROE) can be expressed as

$$
\begin{aligned}
& r_{t} \equiv \log \left(\frac{M_{t}+D_{t}}{M_{t-1}}\right)=\log \left(1+\frac{\Delta M_{t}+D_{t}}{M_{t-1}}\right)=\log \left(1+R_{t}\right) \\
& e_{t} \equiv \log \left(\frac{B_{t}+D_{t}}{B_{t-1}}\right)=\log \left(1+\frac{\Delta B_{t}+D_{t}}{B_{t-1}}\right)=\log \left(1+E_{t}\right)
\end{aligned}
$$

where ROE is denoted by $e_{t}=\log \left(1+X_{t} / B_{t-1}\right)$, the $\log$ stock return by $r_{t}=\log \left(1+R_{t}\right)$, and the simple stock return by $R_{t}$.

Substituting the $\log$ dividend-growth rate, $\Delta d_{t}$, the $\log$ dividend-price ratio, $\delta_{t}$, and the $\log$ dividend-to-book-equity ratio, $\gamma_{t} \equiv d_{t}-b_{t}$, to the return definitions (A1.2) and (A1.3):

$$
\begin{aligned}
& r_{t}=\log \left(\exp \left(-\delta_{t}\right)+1\right)+\Delta d_{t}+\delta_{t-1} . \\
& e_{t}=\log \left(\exp \left(-\gamma_{t}\right)+1\right)+\Delta d_{t}+\gamma_{t-1} .
\end{aligned}
$$

The nonlinear functions (A1.4) and (A1.5) can be approximated around $\hat{\delta}$ and $\hat{\gamma}$. Specifically, use some convex combination of the unconditional means of the variables as an expansion point for both functions. Subtracting $r_{t}$ from $e_{t}$, the approximate expression is

$$
e_{t}-r_{t}=\log \left(\exp \left(-\gamma_{t}\right)+1\right)-\log \left(\exp \left(-\delta_{t}\right)+1\right)+\left(\gamma_{t-1}-\delta_{t-1}\right) \approx \rho \theta_{t}-\theta_{t-1} .
$$

Above, the log book-to-market ratio is denoted by $\theta_{t}$. Note that as dividend yields drop, the approximation becomes more accurate, while $\rho$ approaches unity.

Next, the one period approximation is iterated forward to yield:

$$
\theta_{t-1}=\sum_{j=0}^{N} \rho^{j} r_{t+j}-\sum_{j=0}^{N} \rho^{j} e_{t+j}+\sum_{j=0}^{N} \rho^{j} \xi_{t+j}+\rho^{N+1} \theta_{t+N}
$$


$\xi_{t}$ denotes the approximation error in equation (A1.7). Because $\rho<1$, the limit $N \rightarrow \infty$ of equation (A1.7) converges to

$$
\theta_{t-1}=k_{t-1}+\sum_{j=0}^{\infty} \rho^{j} r_{t+j}-\sum_{j=0}^{\infty} \rho^{j} e_{t+j}
$$

The approximation error of equation (A1.8) is defined as $k_{t-1} \equiv \sum_{j=0}^{\infty} \xi_{t+j}$.

Equation (A1.8) allows one to decompose the unexpected stock return into an expected-return component and a cash-flow component, along the lines of Campbell (1991). We take the change in expectations of (A1.8) from $t-1$ to $t$ and reorganize:

$$
r_{t}-E_{t-1} r_{t}=\Delta E_{t} \sum_{j=0}^{\infty} \rho^{j} e_{t+j}-\Delta E_{t} \sum_{j=1}^{\infty} \rho^{j} r_{t+j}+\kappa_{t},
$$

where $\Delta E_{t}$ denotes the change in expectations from $t-1$ to $t$ (i.e., $\left.E_{t}(\cdot)-E_{t-1}(\cdot)\right)$.

Which value to pick for $\rho$ is an empirical question. We follow Vuolteenaho (2002) and use an OLS regression to pick the discount coefficient. (We regress beginning-of-the-period log book-to-market plus log profitability minus log return on end-of-the-period log book book-to-market.) In our data, a 99.82 percent $\mathrm{R}^{2}$ is achieved with $\rho=.97$. Because $\rho$ is estimated accurately and our main results are not sensitive to the $\rho$-choice, we use this $\rho$-value in the analysis and treat it as a constant. Further experiments performed by Vuolteenaho (2002) show that the multi-period approximation is very accurate in a sample similar to ours. Furthermore, the results of this paper are insensitive to small changes in the discount coefficient: All of the main empirical results can be reproduced with $\rho$ set to 0.95 or 1.00 .

\section{Appendix 2: Data}

\section{A. CRSP-COMPUSTAT data}

The basic data come from the CRSP-COMPUSTAT intersection. The Center for Research in Securities Prices (CRSP) monthly stock file contains monthly prices, shares outstanding, dividends and returns for NYSE, AMEX, and NASDAQ stocks. The COMPUSTAT annual research file contains the relevant accounting information for most publicly traded US stocks.

In order to be included in our sample, a firm-year must satisfy the following COMPUSTAT data requirements. First, we require all firms to have a December fiscal-year end of $t-1$, in order to align accounting variables across firms. Second, a firm must have $t-1, t-2$, and $t-3$ book equity available, where $t$ denotes time in years. A number of CRSP data requirements must also be satisfied. A valid market-equity 
figure must be available for $t-1, t-2$, and $t-3$. We require that there is a valid trade during the month immediately preceding the period $t$ return. This requirement ensures that the return predictability is not spuriously induced by stale prices or other similar market micro-structure issues. We also require at least one monthly return observation during each of the preceding five years, from $t-1$ to $t-5$. In addition, we screen out clear data errors and mismatches by excluding firms with $t-1$ market equity less than $\$ 10$ million and book-to-market more than 100 or less than 1/100. We carefully avoid imposing any COMPUSTAT or CRSP requirements on year $t$ data, because these data are used in the dependent variables of our regressions.

The stock returns are calculated as follows. The simple stock return is an annual value-weight return on a firm's common stock issues (typically one). If no return data are available, we substitute zeros for both returns and dividends. Annual returns are compounded from monthly returns, recorded from the beginning of July to the end of June. Delisting returns are included when available in CRSP. If a firm is delisted but the delisting return is missing, we investigate the reason for disappearance. If the delisting is performancerelated, we assume a -30 percent delisting return. Otherwise, we assume a zero delisting return. ${ }^{10}$

Market equity (combined value of all common stock classes outstanding) is taken from CRSP as of the end of June. If the year $t$ market equity is missing, we compound the lagged market equity with return without dividends.

For book equity, we prefer COMPUSTAT data item 60, but if it is unavailable we use item 235 . Also, if short- and/or long-term deferred taxes are available (data items 35 and 71), we add them to book equity. If both data items 60 and 235 are unavailable, we proxy book equity by the last period's book equity plus earnings less dividends. If neither earnings nor book equity is available, we assume that the book-tomarket ratio has not changed and compute the book equity proxy from the last period's book-to-market and this periods market equity. We treat negative or zero book equity values as missing.

GAAP ROE is the earnings over the last period's book equity, measured according to the U.S. Generally Accepted Accounting Principles. We use the COMPUSTAT data item 172, earnings available for common. When earnings are missing, earnings is computed as the change in book equity plus dividends. In every case, we do not allow the firm to lose more than its book equity. That is, we define the net income as maximum of reported net income (or clean-surplus net income, if earnings are not reported) and negative of the beginning of the period book equity. Hence, the minimum GAAP ROE is truncated to -100 percent. 
We calculate leverage as book equity over the sum of book equity and book debt. The book debt is the sum of debt in current liabilities (34), total long-term debt (9), and preferred stock (130).

The identities necessitate the use of $\log$ transforms of stock return, profitability and the book-tomarket ratio. The log transformations may cause problems if some stock returns and/or ROEs are close to 100 percent or if some of the book-to-market ratios are close to zero or infinity. We follow Vuolteenaho (2002) and solve this complication by redefining the firm as a portfolio of 90 percent common stock and 10 percent Treasury-bills using market values. Every period, the portfolio is rebalanced to these weights. This affects not only stock return and accounting return on equity, but also the book-to-market equity, pulling this ratio slightly towards one. After adding this risk-free investment, the ratios and returns are sufficiently well behaved for $\log$ transformations. Simple market and accounting returns on this portfolio closely approximate simple returns on the firm's common stock only. The accounting identities hold for the transformed quantities. Furthermore, this transformation method is superior to purely statistical transformations (such as the Box-Cox transformation), because the transformed quantities still correspond to an investment strategy. The results are robust to moderate perturbations $(+/-0.025)$ of the T-bill weight.

\section{B. SPECTRUM data}

A 1978 amendment to the Securities and Exchange Act of 1934 required all institutions with greater than $\$ 100$ million of securities under discretionary management to report their holdings to the SEC. Holdings are reported quarterly on the SEC's form 13F; all common-stock positions greater than 10,000 shares or $\$ 200,000$ must be disclosed. These reports are available in electronic form back to 1980 from CDA/Spectrum, a firm hired by the SEC to process the $13 \mathrm{~F}$ filings. Our data include the quarterly reports from the first quarter of 1980 through the fourth quarter of 1999. Throughout this paper, we use “institution", "large institution", and "manager" as synonyms for "an institution that files a 13F".

On the $13 \mathrm{~F}$, each manager must report all securities over which they exercise sole or shared investment discretion. In cases where investment discretion is shared by more than one institution, care is taken to prevent double counting. Spectrum officials have told us that they believe that duplication is rare. Once an institution enters the $13 \mathrm{~F}$ sample, it is assigned a manager type by Spectrum. The five types are (1) bank, (2) insurance company, (3) investment company (mutual fund), (4) investment advisor, and (5) other. The first three categories are self-explanatory; the investment advisor category includes most of the large brokerage firms; the "other" category includes pension funds and university endowments. These 
categorizations are not always precise; for example, brokerage firms with mutual fund subsidiaries will fall into category (3) if the mutual funds are deemed by Spectrum to make up more than 50 percent of the total $13 \mathrm{~F}$ assets for that manager and into category (4) otherwise. Spectrum does not provide information to allow more precise partitioning of the data. It is also possible for a manager to be reclassified over time if Spectrum determines that the institution's main business has changed.

The Spectrum 13F holdings file contains three columns: date, CUSIP, identifier for the institution, and number of shares held in that stock by that institution on that date. All dates are end-of-quarter (3/31, $6 / 30,9 / 30$, or 12/31). For each CUSIP and date we simply sum up the shares held by all institutions in the sample to get total institutional holdings of the security at the end of that quarter. We do not drop firms without SPECTRUM data from our sample: Firms with no SPECTRUM data are recorded as having zero institutional ownership. We then match each CUSIP to a CRSP PERMNO, the permanent number CRSP assigns to that security. Holdings associated with CUSIPs for which we found no associated PERMNO are ignored; these account for a very small fraction of institutional holdings (future drafts will include additional CUSIPs which we are currently hand-matching to PERMNOs). Some companies have multiple equity securities associated with them; CRSP uniquely identifies each firm with a permanent company number, or PERMCO. We value-weight returns and institutional holding percentages of the different share classes (PERMNOs) associated with each PERMCO. This gives us one return and one institutional ownership percentage associated with each set of accounting data.

Our primary results are based on annual vector autoregressions. In these VARs we use end-of-year $t$ 1 accounting information to predict returns from July of year $t$ through June of year $t+1$. We use institutional ownership data as of June 30 of year $t$ as the variable corresponding to the returns over this period. However, the VAR results are robust to using the March 31 or December 31 (of the previous year) institutional ownership instead. Unlike the VARs, Table I uses the change in institutional ownership from the end of December of year $t-2$ to the end of June of year $t$.

In some of our tests we use monthly data. For this purpose we compute the percentage of institutional ownership at the end of each quarter and assume that the number stays constant over the subseqent three months. In this way, we can compute monthly returns on the aggregate institututional portfolio. We define all outstanding shares not held by 13F institutions to be "individual" or "household" holdings. (Our "individual" holdings thus contain assets controlled by very small financial intitutions, but 
these make up only a tiny percentage of the category.) Therefore, for each stock the individual holding fraction is simply one minus the institutional ownership.

\section{Appendix 3: Estimation of the random-coefficient model}

The random-coefficient model is estimated with the algorithm described by Maddala, Trost, Li, and Joutz (1997), which produces maximum-likelihood estimates. In our RCM implementation, firm i's data are assumed to be generated from a VAR model:

$$
z_{i, t}=\mathrm{A}_{i}+\Gamma_{i} z_{i, t-1}+u_{i, t}, \quad u_{i, t} \sim \text { i.i.d.N }\left(0, \Sigma_{i}\right) .
$$

Firm i's intercept vector and transition matrix are assumed to be drawn from the following normal distribution:

$$
\operatorname{vec}\left(\left[\mathrm{A}_{i} \Gamma_{i}\right]^{\prime}\right) \equiv \beta_{i} \sim \text { i.i.d.N }(\mu, \Omega)
$$

Stack the data and define

$$
y_{i} \equiv\left[\begin{array}{c}
z_{i, 1} \\
\vdots \\
z_{i, T_{i}}
\end{array}\right], \quad y=\left[\begin{array}{c}
Y_{1} \\
\vdots \\
Y_{N}
\end{array}\right], \quad Z_{i, t} \equiv\left[\begin{array}{cccc}
1 & z_{i, t}^{\prime} & \cdots & 0 \\
\vdots & \ddots & \vdots \\
0 & \cdots & 1 & z_{i, t}^{\prime}
\end{array}\right], \quad X_{i} \equiv\left[\begin{array}{c}
Z_{i, 0} \\
\vdots \\
Z_{i, T_{i}-1}
\end{array}\right], \quad X=\left[\begin{array}{c}
X_{1} \\
\vdots \\
X_{N}
\end{array}\right]
$$

Together, these assumptions give raise to the following conditional log likelihood function:

$$
\begin{aligned}
L\left(\beta_{i}, \Sigma_{i,} \mu, \Omega \mid y, X\right)= & \text { constant } \\
& -\sum_{i=1}^{N} \frac{T_{i}}{2} \ln \left|\Sigma_{i}\right|-\frac{1}{2} \sum_{i=1}^{N}\left(y_{i}-X_{i} \beta_{i}\right)^{\prime} \Sigma_{i}^{-1}\left(y_{i}-X_{i} \beta_{i}\right) \\
& -\frac{N}{2} \ln \left|\Omega_{i}\right|-\frac{1}{2} \sum_{i=1}^{N}\left(\beta_{i}-\mu\right)^{\prime} \Omega^{-1}\left(\beta_{i}-\mu\right)
\end{aligned}
$$

This log likelihood function can be maximized by successive iterations of the following equations:

$$
\begin{gathered}
\beta_{i}=\left(X_{i}^{\prime} \Sigma_{i}^{-1} X_{i}+\Omega^{-1}\right)^{-1}\left(X_{i}^{\prime} \Sigma_{i}^{-1} y_{i}+\Omega^{-1} \mu\right) \\
\mu=\frac{1}{N} \sum_{i=1}^{N} \beta_{i} \\
\Sigma_{i}=\frac{1}{T_{i}}\left(y_{i}-X_{i} \beta_{i}\right)^{\prime}\left(y_{i}-X_{i} \beta_{i}\right) \\
\Omega_{i}=\frac{1}{N} \sum_{i=1}^{N}\left(\beta_{i}-\mu\right)\left(\beta_{i}-\mu\right)^{\prime}
\end{gathered}
$$

Since some firms have fewer time-series observations than there are equations in the VAR system, inverting some of the firm-specific error covariance matrices is problematic. Therefore, in the step 
described by equation (7), we pool the data for firms that have fewer time series data points than three plus the number of prediction variables per equation (including constant). As a consequence, these firms share a common error covariance matrix.

Starting from reasonable values of $\mu$ and $\Omega$, we iterate equations (A3.5) - (A3.8) until convergence. In the systems we have estimated, convergence is fast and reliable. Typically, less than one hundred iterations are needed to satisfy our convergence criteria. 


\section{References}

Ang, Andrew, Joe Chen, and Yuhang Xing, 2001, Downside risk and the momentum effect, Columbia Business School working paper.

Barberis, Nicholas C., Andrei Shleifer, and Robert W. Vishny, 1998. A model of investor sentiment. Journal of Financial Economics 49, 307-343.

Beneish, Messod D., and Robert E. Whaley, An anatomy of the 'S\&P Game': The effect of changing rules, Journal of Finance 51, 1909-1930.

Bernard, Victor L., and Jacob K. Thomas, 1989, Post-earnings-announcement drift: Delayed price response or risk premium?, Journal of Accounting Research 27, 1-36.

Bernard, Victor L., and Jacob K. Thomas, 1990, Evidence that stock prices do not fully reflect the implications of current earnings for future earnings, Journal of Accounting and Economics 13, 305-340.

Beveridge, Stephen, and Charles R. Nelson, 1981, A new approach to decomposition of economic time series into permanent and transitory components with particular attention to measurement of the "Business cycle," Journal of Monetary Economics 7, 151-174.

Black, Fischer, Michael C. Jensen, and Myron Scholes, 1972, The capital asset pricing model: Some empirical tests, in Michael Jensen ed.: Studies in the Theory of Capital Markets, New York: Praeger.

Campbell, John Y., 1991, A variance decomposition for stock returns, Economic Journal 101, 57-179.

Chan, K. C. Chan, Narasimhan Jegadeesh, and Josef Lakonishok, 1996, Momentum strategies, Journal of Finance 51, 1681-1713.

Chen, Hsiu-Lang, Narasimhan Jegadeesh, and Russ Wermers, 2000, The value of active mutual fund management: an examination of the stockholdings and trades of fund managers, Journal of Financial and Quantitative Analysis 35, 343-368.

Chevalier, Judith and Glenn Ellison, 1999, Career concerns of mutual fund managers, Quarterly Journal of Economics 114, 389-432.

Cohen, Randolph B, 2000, Asset allocation decisions of institutions and individuals, Working paper, Harvard Business School. 
Daniel, Kent D., Mark Grinblatt, Sheridan Titman, and Russ Wermers, 1997, Measuring mutual fund performance with characteristic-based benchmarks, Journal of Finance 52, 1035-1058.

Daniel, Kent D., David Hirshleifer, and Avanidhar Subrahmanyam, 1998, Investor psychology and securities market under- and overreactions, Journal of Finance 53, 1839-1885.

DeBondt, Werner F. M. and Richard H. Thaler, 1985, Does the stock market overreact?, Journal of Finance $40,557-581$.

Del Guercio, Diane, 1996, The distorting effect of prudent-man laws on institutional equity investments, Journal of Financial Economics 40, 31-62.

DeLong, J. Bradford, Andrei Shleifer, Lawrence H. Summers, and Robert J. Waldmann, 1990, Positivefeedback investment strategies and destabilizing rational speculation, Journal of Finance 45, 374397.

Dimson, Elroy, and Andrew Jackson, 2001, High frequency performance monitoring, Journal of Portfolio Management, forthcoming

Efron, Bradley, 1992, Jackknife, the Bootstrap and Other Resampling Plans, CBMS-NSF Regional Conference Series in Applied Mathematics 38, SIAM, Philadelphia, PA.

Fama, Eugene F., 1998, Market efficiency, long-term returns, and behavioral finance, Journal of Financial Economics 49, 283-306.

Fama, Eugene F. and James MacBeth, 1973, Risk, return and equilibrium: Empirical tests, Journal of Political Economy 81, 607-636.

Falkenstein, Eric, 1996, Preferences for stock characteristics as revealed by mutual fund portfolio holdings, Journal of Finance 51, 111-135.

Friedman, Milton, 1953, Essays in Positive Economics, University of Chicago Press.

Grinblatt, Mark, Matti Keloharju, 2000a, The investment behavior and performance of various investortypes: A study of Finland's unique data set, Journal of Financial Economics 55, 43-67.

Grinblatt, Mark, Matti Keloharju, 2000b, What makes investors trade?, Journal of Finance, forthcoming. Grinblatt, Mark, Sheridan Titman, and Russ Wermers, 1995, Momentum investment strategies, portfolio performance, and herding: A study of mutual fund behavior, American Economic Review 85, 1088-1105. 
Gompers, Paul A., and Andrew Metrick, 2001, Institutional investors and equity prices, Quarterly Journal of Economics 116, 229-260.

Harris, Lawrence, and Eithan Gurel, 1986, Price and volume effects associated with changes on the S\&P 500 list: New evidence for the existence of price pressures, Journal of Finance 26, 71-95.

Haugen, Robert A., and Nardin L. Baker, 1996, Commonality in the determinants of expected stock returns, Journal of Financial Economics 41, 401-439.

Hong, Harrison, Terence Lim, and Jeremy C. Stein, 2000, Bad news travels slowly: Size, analyst coverage, and the profitability of momentum strategies, Journal of Finance 55, 265-295.

Hong, Harrison, and Jeremy C. Stein, 1999, A unified theory of underreaction, momentum trading, and overreaction in asset markets, Journal of Finance 54, 2143-2184.

Jegadeesh, Narasimhan, and Sheridan Titman, 1993, Returns to buying winners and selling losers: implications for stock market efficiency, Journal of Finance 48, 65-91.

Jegadeesh, Narasimhan, and Sheridan Titman, 2001, Profitability of momentum strategies: An evaluation of alternative explanations, Journal of Finance 56, 699-720.

Lakonishok, Josef, Andrei Shleifer, and Robert W. Vishny, 1992a, The impact of institutional trading on stock prices, Journal of Financial Economics 32, 23-43.

Lakonishok, Josef, Andrei Shleifer, and Robert W. Vishny, 1992b, The structure and performance of the money management industry, Brookings Papers on Economic Activity: Microeconomics, 339-391.

Lee, Lung-Fei, and William E. Griffiths, 1979, The prior likelihood and best linear unbiased prediction in stochastic coefficient linear models, Center for Economic Research discussion paper 79-107, University of Minnesota.

Lettau, Martin, and Sydney Ludvigson, 2001, Resurrecting the (C)CAPM: A cross-sectional test when risk premia are time-varying, forthcoming in the Journal of Political Economy.

Lynch, Anthony W., and Richard R. Mendenhall, New evidence on stock price effects associated with changes in the S\&P 500, Journal of Business 70, 351-384.

Maddala, G. S., Robert P. Trost, Hongyi Li, and Frederick Joutz, 1997, Estimation of short-run and long-run elasticities of energy demand from panel data using shrinkage estimators, Journal of Business \& Economic Statistics 15, 90-100. 
Michaely, Roni, Richard H. Thaler, and Kent Womack, 1995, Price reactions to dividend initiations and omissions: Overreaction or drift?, Journal of Finance 50, 573-608.

Nofsinger, John R. and Richard W. Sias, 1999, Herding and feedback trading by institutional and individual investors, Journal of Finance 54, 2263-2295.

Pastor, Lubos, and Robert F. Stambaugh, 2001, Liquidity risk and expected stock returns, NBER Working Paper 8462.

Pirinsky, Christo A., 2000, Are financial institutions better investors? Working paper, Fisher College of Business, The Ohio State University.

Rogers, William H., 1983, Analyzing complex survey data, Rand Corporation memorandum, Santa Monica, CA.

Rogers, William H., 1993, Regression standard errors in clustered samples, Stata Technical Bulletin Reprints STB-13 - STB-18, 88-94.

Rosenberg, Barr, Kenneth Reid, and Ronald Lanstein, 1985, Persuasive evidence of market inefficiency, Journal of Portfolio Management 11, 9-17.

Schwartz, Robert, and James Shapiro, 1992, The challenge of institutionalization for equity markets; in Anthony Saunders, ed.: Recent Developments in Finance, Business One Irwin, Homewood, IL.

Shao, Jun, and J. N. K. Rao, 1993, Jackknife inference for heteroscedastic linear regression models, Canadian Journal of Statistics 21, 377-385.

Shleifer, Andrei, 1986, Do demand curves for stocks slope down?, Journal of Finance 41, 579-590.

Shleifer, Andrei, and Robert W. Vishny, 1997, The limits of arbitrage, Journal of Finance 52, 35-55.

Shumway, Tyler G., 1997, The delisting bias in CRSP data, Journal of Finance 52, 327-340.

Swamy, P. A. V. B., 1970, Efficient inference in a random coefficient regression model, Econometrica 38, $3111-323$.

Treynor, Jack, and Fischer Black, 1973, How to use security analysis to improve portfolio selection, Journal of Business 56, 66-86.

Vuolteenaho, Tuomo, 2001, Understanding the aggregate book-to-market ratio and its implications to current equity-premium expectations, working paper, Harvard University Department of Economics.

Vuolteenaho, Tuomo, 2002, What drives firm-level stock returns?, Journal of Finance, forthcoming. 
White, Halbert, 1980, A heteroscedasticity-consistent covariance matrix estimator and a direct test of heteroscedasticity, Econometrica 48, 817-838.

Wermers, Russ, 1999, Mutual fund herding and the impact on stock prices, Journal of Finance 54, 581-622.

Wermers, Russ, 2000, Mutual fund performance: An empirical decomposition into stock-picking talent, style, transaction costs, and expenses, Journal of Finance 55, 1655-1695. 
Table I: Change in institutional ownership as a function of cash-flow proxy and stock return

Each year, the table sorts firms on stock return and a cash-flow proxy and shows the average contemporaneous change in institutional ownership for each sort cell.

Panel A uses accounting return on equity (ROE) as the cash-flow proxy. ROE is measured from the December fiscal year end of year $t-2$ to the December fiscal year end of year $t-1$. Panel B uses cashflow news ( $\left.\widetilde{N}_{c f}\right)$ computed from the VAR of Table III Panel A as the cash-flow proxy.

Stock return is measured from the end of June of year $t-1$ to the end of June of year $t$. The change in institutional ownership is the change in the fraction of shares outstanding owned by institutions from the end of December of year $t-2$ to the end of June of year $t$. The change in institutional ownership is demeaned cross-sectionally. The number in each cell is the time-series average of equal-weight averages. The data consist of 23,501 firm-years and spans period 1983-1998 (16 years).

Panel A: Contemporaneous change in institutional ownership as a function of ROE and stock return

\begin{tabular}{cccccc}
\hline & $\begin{array}{c}\text { Low stock } \\
\text { return }\end{array}$ & 2 & 3 & 4 & $\begin{array}{c}\text { High stock } \\
\text { return }\end{array}$ \\
\hline Low ROE & -0.0487 & -0.0132 & -0.0089 & -0.0013 & -0.0030 \\
2 & -0.0133 & -0.0014 & 0.0042 & 0.0084 & 0.0100 \\
3 & -0.0022 & 0.0070 & 0.0043 & 0.0025 & 0.0090 \\
4 & -0.0076 & 0.0055 & 0.0034 & 0.0049 & 0.0175 \\
High ROE & -0.0081 & 0.0076 & 0.0161 & 0.0114 & 0.0316 \\
\hline
\end{tabular}

Panel B: Contemporaneous change in institutional ownership as a function of VAR cash-flow news and stock return

\begin{tabular}{cccccc}
\hline & $\begin{array}{c}\text { Low stock } \\
\text { return }\end{array}$ & 2 & 3 & 4 & $\begin{array}{c}\text { High stock } \\
\text { return }\end{array}$ \\
\hline Low $N_{c f}$ & -0.0389 & -0.0588 & -0.1324 & -0.2628 & -0.2967 \\
2 & 0.0117 & 0.0013 & -0.0231 & -0.0639 & -0.2903 \\
3 & 0.0239 & 0.0231 & 0.0072 & -0.0105 & -0.1229 \\
4 & 0.0391 & 0.0400 & 0.0296 & 0.0144 & -0.0080 \\
High $N_{c f}$ & 0.0521 & 0.0728 & 0.0830 & 0.0478 & 0.0412 \\
\hline
\end{tabular}




\section{Table II: Descriptive statistics}

Panel A reports means, standard deviations, and percentiles (minimum, 25 $5^{\text {th }}, 50^{\text {th }}, 75^{\text {th }}$, and maximum) of $\log$ return, $r$; $\log$ US GAAP return on equity, $e^{\text {GAAP }}$; $\log$ book-to-market, $\theta$; the fraction of institutional ownership, if; and the change in institutional-ownership fraction, dif. Panel B reports the contemporaneous correlations and Panel $\mathrm{C}$ the first-order cross- and autocorrelations of market-adjusted (i.e., cross-sectionally demeaned) variables. Appendix B contains the details of data sources and variable definitions. The annual data set consists of 23,501 firm-years and spans period 1983-1998 (16 years). The descriptive statistics are estimated from pooled data.

\begin{tabular}{rrrrrrrr}
\multicolumn{7}{l}{ Panel A: Basic descriptive statistics } \\
\hline Variable & Mean & St. Dev. & Min & $25 \%$-pct & Median & $75 \%$-pct & Max \\
\hline$r$ & 0.074 & 0.343 & -2.185 & -0.093 & 0.094 & 0.268 & 2.757 \\
$e^{G A A P}$ & 0.027 & 0.353 & -2.526 & 0.036 & 0.095 & 0.143 & 3.919 \\
$\theta$ & -0.389 & 0.608 & -4.449 & -0.754 & -0.351 & 0.008 & 3.557 \\
if & 0.363 & 0.226 & 0.000 & 0.172 & 0.351 & 0.540 & 0.986 \\
dif & 0.005 & 0.106 & -0.957 & -0.022 & 0.008 & 0.045 & 0.930 \\
\hline
\end{tabular}

Panel B: Contemporaneous correlations, market-adjusted data

\begin{tabular}{|c|c|c|c|c|c|}
\hline Variable & $\widetilde{r}$ & $\tilde{e}^{G A A P}$ & $\tilde{\theta}$ & $\tilde{i f}$ & $\tilde{d i f}$ \\
\hline$\tilde{r}$ & 1 & 0.326 & -0.372 & 0.151 & 0.175 \\
\hline$\widetilde{e}^{G A A P}$ & 0.326 & 1 & 0.113 & 0.197 & 0.086 \\
\hline$\tilde{\theta}$ & -0.372 & 0.113 & 1 & -0.136 & -0.06 \\
\hline$\widetilde{i f}$ & 0.151 & 0.197 & -0.136 & 1 & 0.297 \\
\hline$d \tilde{i f}$ & 0.175 & 0.086 & -0.060 & 0.297 & 1 \\
\hline
\end{tabular}

Panel C: First-order cross- and autocorrelations, market-adjusted data

\begin{tabular}{|c|c|c|c|c|c|}
\hline Variable & $\widetilde{r}(t)$ & $\tilde{e}^{G A A P}(t)$ & $\tilde{\theta}(t)$ & $\tilde{i f}(t)$ & $\tilde{d i f} f(t)$ \\
\hline$\widetilde{r}(t-1)$ & 0.142 & 0.318 & -0.216 & 0.142 & 0.048 \\
\hline$\tilde{e}^{G A A P}(t-1)$ & 0.136 & 0.534 & 0.082 & 0.168 & 0.02 \\
\hline$\tilde{\theta}(t-1)$ & 0.041 & -0.06 & 0.771 & -0.13 & -0.013 \\
\hline$\tilde{i f}(t-1)$ & 0.071 & 0.161 & -0.111 & 0.885 & -0.181 \\
\hline$d \tilde{i} f(t-1)$ & 0.016 & 0.084 & -0.051 & 0.141 & -0.159 \\
\hline
\end{tabular}




\section{Table III: VAR parameter estimates}

The table reports the VAR parameters estimated form the annual panel. Panel A shows pooledregression parameter estimates and Panel B parameter distribution means of random-coefficient model. The model state variables include the market-adjusted log stock return, $\widetilde{r}$, (the first element of the state vector $z$ ); market-adjusted log book-to-market ratio, $\widetilde{\theta}$, (the second element); market-adjusted $\log$ profitability, $\widetilde{e}$, (the third element); and market-adjusted fraction of shares outstanding owned by institutions, $\tilde{i f}$, (the fourth element). The parameters in Panel A correspond to the following system:

$$
z_{i, t}=\Gamma z_{i, t-1}+u_{i, t}, \quad \Sigma=E\left(u_{i, t} u_{i, t}^{\prime}\right)
$$

The parameters in Panel B correspond the VAR implied by $\mu$ and $\Sigma$ in the following system:

$$
z_{i, t}=\mathrm{A}_{i}+\Gamma_{i} z_{i, t-1}+u_{i, t}, \quad \Sigma_{i}=E\left(u_{i, t} u_{i, t}^{\prime}\right), \quad\left[\mathrm{A}_{i}^{\prime} \operatorname{vec}\left(\Gamma_{i}\right)^{\prime}\right]^{\prime} \sim N(\mu, \Omega), \quad \Sigma=\frac{1}{N} \sum_{i=1}^{N} \Sigma_{i}
$$

We report up to three numbers for each parameter. The first number (bold) in Panel $\mathrm{A}$ is a weighted least squares estimate of the parameter, where observations are weighted such that each cross-section receives an equal weight. The first number (bold) in Panel B is a maximum-likelihood estimate of the mean of the firm-specific VAR parameters. Details of the estimation algorithm are documented in Appendix 3. The second number (in parentheses) is a robust standard error computed using Rogers's $(1983,1993)$ method (details of the method are described by Vuolteenaho (2002)). The third number (in brackets) is a robust jackknife standard error computed using the jackknife method of Shao and Rao (1993).

Panel A: Pooled-data coefficient estimates for the first order market-adjusted VAR

(estimate), (s.e.), [j.s.e.]

\begin{tabular}{ccccc|cccc}
\hline & $\Gamma$ & & & & $\boldsymbol{\Sigma}$ & & & \\
\hline$\widetilde{r}_{t}$ & $\mathbf{0 . 1 6 9 4}$ & $\mathbf{0 . 0 6 0 9}$ & $\mathbf{0 . 0 9 8 6}$ & $\mathbf{0 . 0 7 5 9}$ & $\mathbf{0 . 1 0 0 9}$ & $-\mathbf{0 . 0 7 8 2}$ & $\mathbf{0 . 0 2 5 8}$ & $\mathbf{0 . 0 0 5 8}$ \\
& $(0.0334)$ & $(0.0169)$ & $(0.0210)$ & $(0.0161)$ & $(0.0063)$ & $(0.0056)$ & $(0.0019)$ & $(0.0009)$ \\
& {$[0.0349]$} & {$[0.0176]$} & {$[0.0218]$} & {$[0.0166]$} & {$[0.0065]$} & {$[0.0058]$} & {$[0.0019]$} & {$[0.0009]$} \\
\hline$\widetilde{\theta}_{t}$ & $\mathbf{0 . 1 5 9 3}$ & $\mathbf{0 . 8 2 2 9}$ & $\mathbf{0 . 0 9 7 0}$ & $-\mathbf{0 . 0 6 8 9}$ & -0.0782 & $\mathbf{0 . 1 3 3 0}$ & $\mathbf{0 . 0 2 4 6}$ & $-\mathbf{0 . 0 0 3 3}$ \\
& $(0.0256)$ & $(0.0215)$ & $(0.0266)$ & $(0.0175)$ & $(0.0056)$ & $(0.0069)$ & $(0.0027)$ & $(0.0009)$ \\
& {$[0.0267]$} & {$[0.0224]$} & {$[0.0279]$} & {$[0.0181]$} & {$[0.0058]$} & {$[0.0071]$} & {$[0.0028]$} & {$[0.0009]$} \\
\hline$\widetilde{e}_{t}$ & $\mathbf{0 . 2 3 3 6}$ & $\mathbf{0 . 0 0 1 2}$ & $\mathbf{0 . 6 0 4 8}$ & $\mathbf{0 . 0 9 2 1}$ & $\mathbf{0 . 0 2 5 8}$ & $\mathbf{0 . 0 2 4 6}$ & $\mathbf{0 . 0 8 1 0}$ & $\mathbf{0 . 0 0 2 8}$ \\
& $(0.0201)$ & $(0.0079)$ & $(0.0207)$ & $(0.0125)$ & $(0.0019)$ & $(0.0027)$ & $(0.0054)$ & $(0.0003)$ \\
& {$[0.0210]$} & {$[0.0081]$} & {$[0.0214]$} & {$[0.0129]$} & {$[0.0019]$} & {$[0.0028]$} & {$[0.0055]$} & {$[0.0003]$} \\
\hline$\tilde{i f f}_{t}$ & $\mathbf{0 . 0 1 8 5}$ & -0.0035 & $\mathbf{0 . 0 1 4 7}$ & $\mathbf{0 . 9 0 6 2}$ & $\mathbf{0 . 0 0 5 8}$ & -0.0033 & $\mathbf{0 . 0 0 2 8}$ & $\mathbf{0 . 0 1 0 1}$ \\
& $(0.0047)$ & $(0.0027)$ & $(0.0044)$ & $(0.0081)$ & $(0.0009)$ & $(0.0009)$ & $(0.0003)$ & $(0.0009)$ \\
& {$[0.0049]$} & {$[0.0028]$} & {$[0.0046]$} & {$[0.0084]$} & {$[0.0009]$} & {$[0.0009]$} & {$[0.0003]$} & {$[0.0010]$} \\
\hline
\end{tabular}

\begin{tabular}{|c|c|c|c|c|c|c|c|c|c|}
\hline & mean $\mathrm{A}_{\mathrm{i}}$ & $\operatorname{mean} \Gamma_{\mathrm{i}}$ & & & & $\operatorname{mean} \Sigma_{\mathrm{i}}$ & & & \\
\hline$\widetilde{r}_{t}$ & $\begin{array}{l}-0.0161 \\
{[0.0044]}\end{array}$ & $\begin{array}{c}\mathbf{0 . 1 0 5 6} \\
{[0.0259]}\end{array}$ & $\begin{array}{c}\mathbf{0 . 0 8 9 3} \\
{[0.0201]}\end{array}$ & $\begin{array}{c}0.0950 \\
{[0.0231]}\end{array}$ & $\begin{array}{c}\mathbf{0 . 0 7 4 2} \\
{[0.0206]}\end{array}$ & $\begin{array}{c}0.1003 \\
{[0.0072]}\end{array}$ & $\begin{array}{c}-0.0848 \\
{[0.0066]}\end{array}$ & $\begin{array}{c}0.0197 \\
{[0.0023]}\end{array}$ & $\begin{array}{c}0.0060 \\
{[0.0010]}\end{array}$ \\
\hline$\widetilde{\theta}_{t}$ & $\begin{array}{l}-0.0028 \\
{[0.0053]}\end{array}$ & $\begin{array}{c}0.1340 \\
{[0.0251]}\end{array}$ & $\begin{array}{c}0.7358 \\
{[0.0244]}\end{array}$ & $\begin{array}{c}0.0943 \\
{[0.0312]}\end{array}$ & $\begin{array}{l}-0.0572 \\
{[0.0214]}\end{array}$ & $\begin{array}{l}-0.0848 \\
{[0.0066]}\end{array}$ & $\begin{array}{c}0.1330 \\
{[0.0081]}\end{array}$ & $\begin{array}{c}0.0241 \\
{[0.0034]}\end{array}$ & $\begin{array}{l}-0.0040 \\
{[0.0009]}\end{array}$ \\
\hline$\widetilde{e}_{t}$ & $\begin{array}{l}-0.0149 \\
{[0.0053]}\end{array}$ & $\begin{array}{c}0.2002 \\
{[0.0217]}\end{array}$ & $\begin{array}{l}-0.0218 \\
{[0.0090]}\end{array}$ & $\begin{array}{l}0.4867 \\
{[0.0213]}\end{array}$ & $\begin{array}{c}0.0982 \\
{[0.0140]}\end{array}$ & $\begin{array}{c}0.0197 \\
{[0.0023]}\end{array}$ & $\begin{array}{c}0.0241 \\
{[0.0034]}\end{array}$ & $\begin{array}{c}0.0639 \\
{[0.0064]}\end{array}$ & $\begin{array}{c}0.0024 \\
{[0.0003]}\end{array}$ \\
\hline$\tilde{i f}_{t}$ & $\begin{array}{c}-0.0031 \\
{[0.0017]}\end{array}$ & $\begin{array}{c}0.0171 \\
{[0.0051]}\end{array}$ & $\begin{array}{l}-0.0059 \\
{[0.0037]}\end{array}$ & $\begin{array}{c}0.0120 \\
{[0.0060]}\end{array}$ & $\begin{array}{c}0.7832 \\
{[0.0092]}\end{array}$ & $\begin{array}{c}0.0060 \\
{[0.0010]}\end{array}$ & $\begin{array}{c}-0.0040 \\
{[0.0009]}\end{array}$ & $\begin{array}{c}0.0024 \\
{[0.0003]}\end{array}$ & $\begin{array}{l}0.0113 \\
{[0.0011]}\end{array}$ \\
\hline
\end{tabular}

Panel B: RCM-mean $(\mu, \Sigma)$ coefficient estimates for the first order market-adjusted VAR 


\section{Table IV: Responses of price and institutional ownership to cash-flow news}

The table reports derived statistics calculated from the VAR specification of Table III Panel A. The VAR specification has the structure

$$
z_{i, t}=\Gamma z_{i, t-1}+u_{i, t}, \quad \Sigma=E\left(u_{i, t} u_{i, t}^{\prime}\right)
$$

The model variables include the market-adjusted log stock return, market-adjusted log book-to-market ratio, market-adjusted log profitability, and market-adjusted institutional-ownership fraction.

Panel A reports the covariance and correlation matrices of expected-return news, cash-flow news, and institutional-ownership shock. The upper-left section (including diagonal) of the panel shows covariances and the shaded lower-left section correlations. Panel B shows the simple regression coefficients of return and institutional-ownership shock on cash-flow news. Panel $\mathrm{C}$ reports the covariance and correlation matrices of one-period expected return, long-horizon expected return, and the fraction of institutional ownership. The long-horizon expected-return measure is defined as $\widetilde{p}_{r, t-1} \equiv \sum_{j=0}^{\infty} \rho^{j} E_{t-1} \widetilde{r}_{t+j}$. The upper-left section (including diagonal) of the panel shows covariances and the shaded lower-left section correlations.

The first number (bold) is a point estimate computed using the weighted least squares estimates of the parameters. The second number (in brackets) is a robust jackknife standard error computed using the jackknife method of Shao and Rao (1993).

\begin{tabular}{|c|c|c|c|}
\hline & $\begin{array}{c}\text { Expected-return } \\
\text { News }\end{array}$ & $\begin{array}{c}\text { Cash-flow } \\
\text { news }\end{array}$ & $\begin{array}{c}\text { Institutional- } \\
\text { ownership shock }\end{array}$ \\
\hline Expected-return & 0.0619 & 0.0896 & 0.0122 \\
\hline News & {$[0.0208]$} & {$[0.0274]$} & {$[0.0027]$} \\
\hline $\begin{array}{l}\text { Cash-flow } \\
\text { News }\end{array}$ & $\begin{array}{c}0.7713 \\
{[0.0598]}\end{array}$ & $\begin{array}{c}0.2182 \\
{[0.0379]}\end{array}$ & $\begin{array}{c}0.0180 \\
{[0.0029]}\end{array}$ \\
\hline $\begin{array}{c}\text { Institutional- } \\
\text { Ownership shock }\end{array}$ & $\begin{array}{c}0.4871 \\
{[0.0797]}\end{array}$ & $\begin{array}{c}0.3823 \\
{[0.0371]}\end{array}$ & $\begin{array}{c}0.0101 \\
{[0.0010]}\end{array}$ \\
\hline
\end{tabular}

Panel B: Simple regression coefficients

\begin{tabular}{cc}
\hline Stock return & $\mathbf{0 . 5 8 9 3}$ \\
on cash-flow news & {$[0.0616]$} \\
\hline Institutional-ownership shock & $\mathbf{0 . 0 8 2 3}$ \\
on cash-flow news & {$[0.0092]$} \\
\hline
\end{tabular}

Panel C: Covariances and correlations (shaded) of expected returns and insitutional ownership

\begin{tabular}{cccc}
\hline & $\begin{array}{c}\text { One-period } \\
\text { expected return }\end{array}$ & $\begin{array}{c}\text { Long-horizon } \\
\text { expected return }\end{array}$ & $\begin{array}{c}\text { Institutional } \\
\text { ownership }\end{array}$ \\
\hline One-period & $\mathbf{0 . 0 0 8 8}$ & $\mathbf{0 . 0 4 2 8}$ & $\mathbf{0 . 0 1 0 0}$ \\
expected return & {$[0.0027]$} & {$[0.0142]$} & {$[0.0025]$} \\
\hline Long-horizon & $\mathbf{0 . 9 0 7 6}$ & $\mathbf{0 . 2 5 2 4}$ & $\mathbf{0 . 0 8 2 1}$ \\
expected return & {$[0.0349]$} & {$[0.0885]$} & {$[0.0216]$} \\
\hline Institutional & $\mathbf{0 . 4 1 4 7}$ & $\mathbf{0 . 6 3 9 5}$ & $\mathbf{0 . 0 6 5 3}$ \\
ownership & {$[0.0646]$} & {$[0.0949]$} & {$[0.0069]$} \\
\hline
\end{tabular}




\section{Table V: Responses of price and institutional ownership to cash-flow news}

The table reports the cross-sectional percentiles of the firm-specific derived statistics. The firmspecific derived statistics are computed from the firm-specific VAR parameter estimates obtained from a random-coefficient model. The VAR specification has the structure

$$
z_{i, t}=\mathrm{A}_{i}+\Gamma_{i} z_{i, t-1}+u_{i, t}, \quad \Sigma_{i}=E\left(u_{i, t} u_{i, t}^{\prime}\right), \quad\left[\mathrm{A}_{i}^{\prime} \operatorname{vec}\left(\Gamma_{i}\right)^{\prime}\right]^{\prime} \sim N(\mu, \Omega)
$$

The model variables include the market-adjusted log stock return, market-adjusted log book-to-market ratio, market-adjusted log profitability, and market-adjusted institutional-ownership fraction. The table shows the cross-sectional percentiles of variance of expected-return news, $\operatorname{var}\left(\tilde{N}_{r}\right)$; variance of cashflow news $\operatorname{var}\left(\tilde{N}_{c f}\right)$; variance of institutional-ownership shock, $\operatorname{var}(u(\tilde{i f}))$; correlation of expectedreturn news and cash-flow news, $\operatorname{corr}\left(\widetilde{N}_{r}, \widetilde{N}_{c f}\right)$; correlation of expected-return news and institutionalownership shock, $\operatorname{corr}\left(\tilde{N}_{r}, u(\tilde{i f})\right)$; correlation of cash-flow news and institutional-ownership shock, $\operatorname{corr}\left(\tilde{N}_{c f}, u(\tilde{i f})\right)$; the regression coefficient of return on cash-flow news, $b\left(\widetilde{r}, \widetilde{N}_{c f}\right)$; the regression coefficient of institutional-ownership shock on cash-flow news, $b\left(u(\tilde{i f}), \widetilde{N}_{c f}\right)$; correlation of one-period expected return and the level of institutional ownership, $\operatorname{corr}\left(E_{t-1} r_{t}, \widetilde{i f}_{t-1}\right)$; and correlation of long-horizon expected return and the level of institutional ownership, $\operatorname{corr}\left(p_{r, t-1}, \tilde{f}_{t-1}\right)$. The long-horizon expectedreturn is defined as $\widetilde{p}_{r, i, t-1} \equiv \sum_{j=0}^{\infty} \rho^{j}\left(E_{t-1} \widetilde{r}_{i, t+j}-E \widetilde{r}_{i}\right)$.

The first number (bold) is a point estimate. The second number (in brackets) is a robust jackknife standard error computed using the jackknife method of Shao and Rao (1993).

\begin{tabular}{|c|c|c|c|c|c|c|c|}
\hline Percentile & $5^{\text {th }}$ & $10^{\text {th }}$ & $25^{\text {th }}$ & Median & $75^{\text {th }}$ & $90^{\text {th }}$ & $95^{\text {th }}$ \\
\hline \multirow[b]{2}{*}{$\operatorname{var}\left(\widetilde{N}_{r}\right)$} & 0.0189 & 0.0201 & 0.0233 & 0.0271 & 0.0320 & 0.0383 & 0.0438 \\
\hline & {$[0.0068]$} & {$[0.0067]$} & {$[0.0075]$} & {$[0.0085]$} & {$[0.0094]$} & {$[0.0096]$} & [0.0169] \\
\hline \multirow{2}{*}{$\operatorname{var}\left(\widetilde{N}_{c f}\right)$} & 0.1044 & 0.1072 & 0.1125 & 0.1189 & 0.1285 & 0.1631 & 0.2076 \\
\hline & [0.0172] & [0.0161] & [0.0156] & [0.0158] & {$[0.0174]$} & [0.0288] & [0.0497] \\
\hline \multirow{2}{*}{$\operatorname{var}(u(\tilde{i f}))$} & 0.0113 & 0.0113 & 0.0113 & 0.0113 & 0.0113 & 0.0113 & 0.0113 \\
\hline & {$[0.0011]$} & {$[0.0011]$} & {$[0.0011]$} & {$[0.0011]$} & {$[0.0011]$} & {$[0.0011]$} & {$[0.0011]$} \\
\hline \multirow[b]{2}{*}{$\operatorname{corr}\left(\widetilde{N}_{r}, \widetilde{N}_{c f}\right)$} & 0.3440 & 0.3486 & 0.3675 & 0.4034 & 0.4746 & 0.7431 & 0.9005 \\
\hline & [0.1132] & [0.1075] & [0.0978] & [0.0904] & {$[0.0948]$} & [0.1219] & {$[0.0675]$} \\
\hline \multirow{2}{*}{$\operatorname{corr}\left(\tilde{N}_{r}, u(\tilde{i f})\right)$} & 0.1335 & 0.1609 & 0.2100 & 0.2646 & 0.3409 & 0.5276 & 0.5693 \\
\hline & [0.0528] & [0.0592] & [0.0649] & [0.0756] & {$[0.0891]$} & {$[0.0948]$} & [0.0528] \\
\hline \multirow[b]{2}{*}{$\operatorname{corr}\left(\tilde{N}_{c f}, u(\tilde{i f})\right)$} & 0.2595 & 0.2679 & 0.2795 & 0.2893 & 0.2999 & 0.3202 & 0.3335 \\
\hline & {$[0.0304]$} & {$[0.0315]$} & {$[0.0315]$} & [0.0326] & {$[0.0329]$} & [0.0344] & {$[0.0402]$} \\
\hline \multirow[b]{2}{*}{$b\left(\widetilde{r}, \widetilde{N}_{c f}\right)$} & 0.6559 & 0.7322 & 0.7935 & 0.8070 & 0.8104 & 0.8111 & 0.8112 \\
\hline & [0.0819] & {$[0.0551]$} & [0.0593] & [0.0604] & {$[0.0621]$} & {$[0.0630]$} & [0.0632] \\
\hline \multirow[b]{2}{*}{$b\left(u(\tilde{i f}), \widetilde{N}_{c f}\right)$} & 0.0753 & 0.0822 & 0.0873 & 0.0888 & 0.0892 & 0.0893 & 0.0893 \\
\hline & {$[0.0075]$} & {$[0.0077]$} & [0.0094] & {$[0.0096]$} & {$[0.0096]$} & [0.0096] & [0.0096] \\
\hline \multirow[b]{2}{*}{$\operatorname{corr}\left(E_{t-1} r_{t}, \tilde{i f}_{t-1}\right)$} & 0.1335 & 0.1609 & 0.2100 & 0.2646 & 0.3409 & 0.5276 & 0.5693 \\
\hline & {$[0.0528]$} & [0.0592] & [0.0649] & {$[0.0756]$} & {$[0.0891]$} & [0.0948] & [0.0528] \\
\hline \multirow{2}{*}{$\operatorname{corr}\left(p_{r, t-1}, \tilde{i f}_{t-1}\right)$} & 0.2595 & 0.2679 & 0.2795 & 0.2893 & 0.2999 & 0.3202 & 0.3335 \\
\hline & {$[0.0304]$} & {$[0.0315]$} & [0.0319] & [0.0326] & {$[0.0329]$} & [0.0344] & [0.0402] \\
\hline
\end{tabular}




\section{Table VI: Results for size groups}

The table reports the results for different size groups. Panel A assumes that all size quintiles share the same transition matrix $\Gamma$ but may have different error covariance matrices $\Sigma$. Panel B assumes that stocks in different size quintiles have different transition matrices and error covariance matrices. In Panel B, the quintile assignment is assumed to be permanent.

The VAR specification has the structure

$$
z_{i, t}=\Gamma z_{i, t-1}+u_{i, t}, \quad \Sigma(\text { characteristics })=E\left(u_{i, t} u_{i, t}^{\prime} \mid \text { characteristics }\right)
$$

The model variables include the market-adjusted log stock return, $\widetilde{r}$, (the first element of the state vector $z$ ); market-adjusted log book-to-market ratio, $\widetilde{\theta}$, (the second element); market-adjusted log profitability, $\widetilde{e}$, (the third element); and market-adjusted fraction of shares outstanding owned by institutions, $\tilde{f}$, (the fourth element). The characteristic affecting the error covariance matrix is size-group assignment.

For every size group, we report four statistics: the variance of expected-return news, $\operatorname{var}\left(\tilde{N}_{r}\right)$; the variance of cash-flow news, $\operatorname{var}\left(\widetilde{N}_{c f}\right)$; the simple regression coefficient of return on cash-flow news, $b\left(\widetilde{r}, \widetilde{N}_{c f}\right)$; and the simple regression coefficient of institutional-ownership shock on cash-flow news, $b\left(u(\tilde{i f}), \tilde{N}_{c f}\right)$.

For each statistic, we report two numbers. The first number (bold) is a point estimate computed using the weighted least squares estimates of the parameters. The second number (in brackets) is a robust jackknife standard error computed using the jackknife method of Shao and Rao (1993).

\begin{tabular}{|c|c|c|c|c|}
\hline Quintile & $\operatorname{var}\left(\widetilde{N}_{r}\right)$ & $\operatorname{var}\left(\tilde{N}_{c f}\right)$ & $b\left(\widetilde{r}, \widetilde{N}_{c f}\right)$ & $b\left(u(\tilde{i f}), \tilde{N}_{c f}\right)$ \\
\hline Small & $0.1273[0.0434]$ & $0.4234[0.0711]$ & $0.5585[0.0681]$ & $0.0455[0.0058]$ \\
\hline 2 & $0.0738[0.0225]$ & $0.2708[0.0417]$ & $0.5965[0.0611]$ & $0.0800[0.0074]$ \\
\hline 3 & $\mathbf{0 . 0 5 7 2}[0.0174]$ & $0.2062[0.0347]$ & $0.5937[0.0552]$ & $0.1038[0.0147]$ \\
\hline 4 & $\mathbf{0 . 0 3 2 6}[0.0104]$ & $0.1177[0.0225]$ & $0.6255[0.0610]$ & $0.1479[0.0183]$ \\
\hline Big & $0.0187[0.0061]$ & $0.0738[0.0136]$ & $0.6686[0.0643]$ & $0.1375[0.0155]$ \\
\hline Small-Big & $0.1086[0.0382]$ & $0.3496[0.0599]$ & $-0.1100[0.0375]$ & $-0.0920[0.0139]$ \\
\hline
\end{tabular}

Panel B: Size quintiles, permanent group assignment

\begin{tabular}{ccccc}
\hline Quintile & $\operatorname{var}\left(\tilde{N}_{r}\right)$ & $\operatorname{var}\left(\tilde{N}_{c f}\right)$ & $b\left(\widetilde{r}, \tilde{N}_{c f}\right)$ & $b\left(u(\tilde{i f}), \tilde{N}_{c f}\right)$ \\
\hline Small & $\mathbf{0 . 1 3 0 1 [ 0 . 0 5 9 4 ]}$ & $\mathbf{0 . 4 2 0 2 [ 0 . 0 8 5 0 ]}$ & $\mathbf{0 . 5 5 4 5 [ 0 . 0 8 7 5 ]}$ & $\mathbf{0 . 0 3 0 1 [ 0 . 0 0 6 9 ]}$ \\
2 & $\mathbf{0 . 0 7 5 7 [ 0 . 0 3 7 7 ]}$ & $\mathbf{0 . 2 5 1 7 [ 0 . 0 6 2 6 ]}$ & $\mathbf{0 . 5 9 9 4 [ 0 . 0 9 8 7 ]}$ & $\mathbf{0 . 0 6 8 0 [ 0 . 0 1 0 6 ]}$ \\
3 & $\mathbf{0 . 0 2 8 4 [ 0 . 0 1 7 0 ]}$ & $\mathbf{0 . 1 4 7 0 [ 0 . 0 3 2 5 ]}$ & $\mathbf{0 . 7 2 8 9 [ 0 . 0 9 2 6 ]}$ & $\mathbf{0 . 0 6 3 4 [ 0 . 0 2 5 5 ]}$ \\
4 & $\mathbf{0 . 0 1 1 5 [ 0 . 0 0 7 0 ]}$ & $\mathbf{0 . 0 6 4 0 [ 0 . 0 1 1 1 ]}$ & $\mathbf{0 . 8 9 3 1 [ 0 . 1 0 6 9 ]}$ & $\mathbf{0 . 0 7 1 4 [ 0 . 0 2 9 1 ]}$ \\
Big & $\mathbf{0 . 0 0 1 3 [ 0 . 0 0 1 8 ]}$ & $\mathbf{0 . 0 4 0 3 [ 0 . 0 0 9 4 ]}$ & $\mathbf{1 . 0 0 9 0 [ 0 . 0 9 1 3 ]}$ & $\mathbf{0 . 0 7 6 8 [ 0 . 0 4 4 2 ]}$ \\
\hline Small-Big & $\mathbf{0 . 1 2 8 8 [ 0 . 0 5 9 6 ]}$ & $\mathbf{0 . 3 7 9 9 [ 0 . 0 8 2 8 ]}$ & $-\mathbf{0 . 4 5 4 4 [ 0 . 1 2 5 5 ]}$ & $\mathbf{- 0 . 0 4 6 7 [ 0 . 0 4 4 1 ]}$ \\
\hline
\end{tabular}




\section{Table VII : Asymmetric response to good and bad news}

The table documents the asymmetric response of returns and institutional ownership to good and bad cash-flow news. First, we use the VAR model of Table III Panel A to compute the fitted values of the news terms. Second, we regress the market-adjusted stock return and estimated market-adjusted ownership shock on a constant, cash-flow news, and the minimum of zero and cash-flow news:

$$
\left[\begin{array}{c}
\widetilde{r}_{t} \\
u_{t}(\tilde{i f})
\end{array}\right]=\left[\begin{array}{l}
a_{2} \\
a_{2}
\end{array}\right]+\left[\begin{array}{ll}
b_{11} & b_{12} \\
b_{21} & b_{22}
\end{array}\right]\left[\begin{array}{c}
\tilde{N}_{c f, t} \\
\tilde{N}_{c f, t} n e g
\end{array}\right]+\left[\begin{array}{c}
e_{1, t} \\
e_{2, t}
\end{array}\right]
$$

$u(\tilde{i f})$ is the estimated institutional-ownership shock from the VAR of Table III Panel A, $\widetilde{r}$ marketadjusted stock return, $\widetilde{N}_{c f}$ estimated cash-flow news, and $\tilde{N}_{c f} n e g$ minimum of zero and $\tilde{N}_{c f}$.

Panel A shows the regression coefficients estimated from the entire sample. Panels B and C show the regression coefficients for different size groups. Panel B assumes that all size quintiles share the same transition matrix $\Gamma$ in estimation of the cash-flow-news terms. Panel $\mathrm{C}$ uses cash-flow news estimated under the assumptions that stocks in different size quintiles have different transition matrices and that a stock's quintile assignment is permanent.

For each statistic, we report two numbers. The first number (bold) is a point estimate computed using the pooled-OLS estimates of the parameters. The second number (in brackets) is a robust jackknife standard error computed using the jackknife method of Shao and Rao (1993).

Panel A: Asymmetric response to news for all firms

\begin{tabular}{|c|c|c|c|c|}
\hline & $b_{11}\left(\widetilde{r}, \widetilde{N}_{c f}\right)$ & $b_{12}\left(\widetilde{r}, \widetilde{N}_{c f} n e g\right)$ & $b_{21}\left(u(\tilde{i f}), \widetilde{N}_{c f}\right)$ & $b_{22}\left(u(\tilde{i f}), \widetilde{N}_{c f} n e g\right)$ \\
\hline All firms & $0.6582[0.0713]$ & $-0.1076[0.0424]$ & $0.1038[0.0108]$ & $-0.0314[0.0084]$ \\
\hline \multicolumn{5}{|c|}{ Panel B: Size quintiles, common transition matrix } \\
\hline Quintile & $b_{11}\left(\widetilde{r}, \tilde{N}_{c f}\right)$ & $b_{12}\left(\widetilde{r}, \widetilde{N}_{c f} n e g\right)$ & $b_{21}\left(u(\tilde{i f}), \tilde{N}_{c f}\right)$ & $b_{22}\left(u(\tilde{i f}), \widetilde{N}_{c f} n e g\right)$ \\
\hline Small & $0.6837[0.0971]$ & $-0.1782[0.0825]$ & $0.0612[0.0111]$ & $-0.0254[0.0098]$ \\
\hline 2 & $0.6646[0.0833]$ & $-0.1116[0.0650]$ & $0.1154[0.0139]$ & $-0.0568[0.0160]$ \\
\hline 3 & $0.6671[0.0643]$ & $-0.1170[0.0481]$ & $0.1388[0.0142]$ & $-0.0507[0.0154]$ \\
\hline 4 & $0.6347[0.0549]$ & $-0.0442[0.0628]$ & $0.1441[0.0156]$ & $0.0138[0.0315]$ \\
\hline Big & $0.6756[0.1035]$ & $-0.0666[0.1828]$ & $0.1050[0.0082]$ & $0.0715[0.0437]$ \\
\hline Small-Big & $0.0081[0.1235]$ & $-0.1115[0.2429]$ & $-0.0438[0.0135]$ & $-0.0969[0.0489]$ \\
\hline
\end{tabular}

Panel C: Size quintiles, permanent group assignment

\begin{tabular}{|c|c|c|c|c|}
\hline Quintile & $b_{11}\left(\widetilde{r}, \tilde{N}_{c f}\right)$ & $b_{12}\left(\widetilde{r}, \widetilde{N}_{c f} n e g\right)$ & $b_{21}\left(u(\tilde{i f}), \tilde{N}_{c f}\right)$ & $b_{22}\left(u(\tilde{i f}), \widetilde{N}_{c f} n e g\right)$ \\
\hline Small & $0.6833[0.1133]$ & $-0.1972[0.0906]$ & $0.0303[0.0180]$ & $0.0005[0.0182]$ \\
\hline 2 & 0.7049 [0.1252] & $-0.1699[0.0725]$ & $0.0995[0.0240]$ & $-0.0500[0.0237]$ \\
\hline 3 & $0.8487[0.0920]$ & $-0.1788[0.0654]$ & $0.0407[0.0557]$ & $0.0379[0.0544]$ \\
\hline 4 & $0.9419[0.0884]$ & $-0.0869[0.0931]$ & $0.0308[0.0570]$ & $0.0761[0.0645]$ \\
\hline Big & $1.0170[0.1052]$ & $-0.0131[0.2125]$ & $0.0281[0.0661]$ & $0.0993[0.0482]$ \\
\hline Small-Big & $-0.3337[0.1636]$ & $-0.1840[0.2794]$ & $0.0022[0.0674]$ & $-0.0987[0.0532]$ \\
\hline
\end{tabular}




\section{Table VIII: Tests of mean-variance efficiency}

The table tests the mean-variance efficiency of aggregate institutional holdings, aggregate individual holdings, holdings of disaggregate groups of institutions, and the CRSP VW portfolio. Panel A shows descriptive statistics. Panel B shows the Black-Jensen-Scholes (1972) test of mean-variance efficiency of a given portfolio. As the test asset, we use a portfolio that goes long in stocks that have experienced positive cash-flow news in the past and goes short in stocks that have experienced negative cash-flow news in the past (labeled "Ncf portfolio"). In this portfolio, the stocks have weights proportional to their past cash-flow news. The cash-flow-news series are estimated using past data only, using a first-order VAR with market-adjusted log return, ROE, and book-to-market in the state vector. The VAR data are the 1954-1998 CRSP-COMPUSTAT intersection used by Vuolteenaho (2002). Panel $\mathrm{C}$ regresses the portfolio returns on the returns of the CRSP VW portfolio and the zero-investment cashflow-news portfolio. Appendix 2 contains descriptions of disaggregate groups of institutions.

Panel A: Descriptive statistics, monthly returns 7/1981-12/1998.

\begin{tabular}{cccc}
\hline Portfolio return & Mean & Standard dev. & Sharpe ratio \\
\hline CRSP VW - RF & $0.81 \%$ & $4.37 \%$ & 0.1857 \\
Ncf portfolio & $0.74 \%$ & $3.83 \%$ & 0.1926 \\
Institutions - RF & $0.87 \%$ & $4.54 \%$ & 0.1908 \\
Individuals - RF & $0.75 \%$ & $4.25 \%$ & 0.1775 \\
Banks - RF & $0.89 \%$ & $4.34 \%$ & 0.2063 \\
Insurance companies - RF & $0.87 \%$ & $4.52 \%$ & 0.1926 \\
Mutual funds- RF & $0.87 \%$ & $4.71 \%$ & 0.1849 \\
Investment advisors - RF & $0.85 \%$ & $4.72 \%$ & 0.1809 \\
Other institutions - RF & $0.84 \%$ & $4.41 \%$ & 0.1896 \\
\hline
\end{tabular}

Panel B: Time-series regressions to test efficiency, monthly returns 7/1981-12/1998.

\begin{tabular}{ccccc}
\hline Portfolio return & Alpha (t-stat) & Beta (t-stat) & Dependent variable & $\mathrm{R}^{2}$ \\
\hline Ncf portfolio & $0.75 \%(2.78)$ & $-0.014(-0.22)$ & CRSP VW - RF & 0.00 \\
Ncf portfolio & $0.74 \%(2.74)$ & $-0.001(-0.01)$ & Institutions - RF & 0.00 \\
Ncf portfolio & $0.76 \%(2.82)$ & $-0.028(-0.45)$ & Individuals - RF & 0.00 \\
Ncf portfolio & $0.73 \%(2.70)$ & $0.010(0.16)$ & Banks - RF & 0.00 \\
Ncf portfolio & $0.74 \%(2.75)$ & $-0.004(-0.06)$ & Insurance companies - RF & 0.00 \\
Ncf portfolio & $0.74 \%(2.74)$ & $-0.002(-0.03)$ & Mutual funds- RF & 0.00 \\
Ncf portfolio & $0.74 \%(2.76)$ & $-0.006(-0.10)$ & Investment advisors - RF & 0.00 \\
Ncf portfolio & $0.74 \%(2.73)$ & $0.001(0.02)$ & Other institutions - RF & 0.00 \\
\hline
\end{tabular}

Panel C: Time-series regressions to measure portfolio weights, monthly returns 7/1981-12/1998.

\begin{tabular}{ccccc}
\hline Portfolio return & Alpha (t-stat) & $\begin{array}{c}\text { Weight on } \\
\text { CRSP VW (t-stat) }\end{array}$ & $\begin{array}{c}\text { Weight on the } \\
\text { Ncf portfolio (t-stat) }\end{array}$ & $\mathrm{R}^{2}$ \\
\hline Institutions - RF & $0.01 \%(0.49)$ & $1.0379(219)$ & $0.0172(3.17)$ & 0.996 \\
Individuals - RF & $-0.02 \%(-0.44)$ & $0.9645(122)$ & $-0.0178(-1.97)$ & 0.986 \\
Banks - RF & $0.07 \%(2.42)$ & $0.9888(161)$ & $0.0300(4.28)$ & 0.992 \\
Insurance companies - RF & $0.02 \%(0.81)$ & $1.0317(200)$ & $0.0133(2.26)$ & 0.995 \\
Mutual funds- RF & $-0.02 \%(-0.43)$ & $1.0754(132)$ & $0.0167(1.81)$ & 0.988 \\
Investment advisors - RF & $-0.03 \%(-0.89)$ & $1.0769(147)$ & $0.0106(1.28)$ & 0.990 \\
Other institutions - RF & $0.00 \%(0.09)$ & $1.0046(136)$ & $0.0191(2.28)$ & 0.989 \\
\hline
\end{tabular}




\section{Table IX: Alternative VAR specifications}

The table reports estimates derived from various estimated VAR specifications. The model state variables include various lags of the market-adjusted log stock return, $\widetilde{r}$; market-adjusted log book-tomarket ratio, $\widetilde{\theta}$; market-adjusted log profitability, $\widetilde{e}$; market-adjusted log leverage (book equity over the sum of book equity and book debt), $\widetilde{e} v$; market-adjusted fraction of shares outstanding owned by institutions, $\tilde{f}$; and cross-sectionally standardized log market equity, siz $e$.

For each specification, the table shows VAR-based estimates of the variance of expected-return news, $\operatorname{var}\left(\tilde{N}_{r}\right)$; variance of cash-flow news $\operatorname{var}\left(\tilde{N}_{c f}\right)$; variance of institutional-ownership shock, $\operatorname{var}(u(\tilde{i f}))$; correlation of expected-return news and cash-flow news, $\operatorname{corr}\left(\widetilde{N}_{r}, \widetilde{N}_{c f}\right)$; correlation of expected-return news and institutional-ownership shock, $\operatorname{corr}\left(\tilde{N}_{r}, u(\tilde{i f})\right)$; correlation of cash-flow news and institutional-ownership shock, $\operatorname{corr}\left(\tilde{N}_{c f}, u(\tilde{i f})\right)$; the regression coefficient of return on cash-flow news, $b\left(\widetilde{r}, \tilde{N}_{c f}\right)$; the regression coefficient of institutional-ownership shock on cash-flow news, $b\left(u(\tilde{i f}), \widetilde{N}_{c f}\right)$; correlation of one-period expected return and the level of institutional ownership, $\operatorname{corr}\left(E_{t-1} r_{t}, \tilde{f}_{t-1}\right)$; and correlation of long-horizon expected return and the level of institutional ownership, $\operatorname{corr}\left(p_{r, t-1}, \tilde{f}_{t-1}\right)$. The long-horizon expected-return is defined as $\widetilde{p}_{r, i, t-1} \equiv \sum_{j=0}^{\infty} \rho^{j} E_{t-1} \widetilde{r}_{i, t+j}$.

We report two numbers for each parameter. The first number (bold) in is a weighted least squares estimate of the parameter, where observations are weighted such that each cross-section receives an equal weight. The second number (in brackets) is a robust jackknife standard error computed using the jackknife method of Shao and Rao (1993). 


\begin{tabular}{|c|c|c|c|c|c|c|c|c|c|}
\hline \multicolumn{3}{|c|}{ var } & \multicolumn{3}{|c|}{ corr } & \multicolumn{2}{|c|}{$U$} & \multicolumn{2}{|c|}{ corr } \\
\hline$\tilde{N}_{r}$ & $\tilde{N}_{c f}$ & $u(\tilde{i f})$ & $\tilde{N}_{r}, \widetilde{N}_{c f}$ & $\widetilde{N}_{r}, u(\tilde{i f})$ & $\tilde{N}_{c f}, u(\tilde{i f})$ & $\widetilde{r}, \tilde{N}_{c f}$ & $u(\tilde{i f}), \widetilde{N}_{c f}$ & $E_{t-1} r_{t}, \tilde{f}_{t-1}$ & $p_{r, t-1}, \tilde{i f}_{t-1}$ \\
\hline \multicolumn{10}{|c|}{ Model 1, predictor variables: $\tilde{r}_{t-1}, \tilde{\theta}_{t-1}, \widetilde{\theta}_{t-2}, \tilde{e}_{t-1}, \tilde{f}_{t-1}$} \\
\hline $\begin{array}{r}0.0620 \\
{[0.0211]}\end{array}$ & $\begin{array}{r}0.2203 \\
{[0.0396]}\end{array}$ & $\begin{array}{r}0.0101 \\
{[0.0010]}\end{array}$ & $\begin{array}{r}0.7763 \\
{[0.0616]}\end{array}$ & $\begin{array}{r}0.4879 \\
{[0.0799]}\end{array}$ & $\begin{array}{r}0.3812 \\
{[0.0374]}\end{array}$ & $\begin{array}{r}0.5882 \\
{[0.0622]}\end{array}$ & $\begin{array}{r}0.0817 \\
{[0.0096]}\end{array}$ & $\begin{array}{r}0.4171 \\
{[0.0639]}\end{array}$ & $\begin{array}{r}0.6441 \\
{[0.0936]}\end{array}$ \\
\hline \multicolumn{10}{|c|}{ Model 2, predictor variables: $\widetilde{r}_{t-1}, \widetilde{\theta}_{t-1}, \widetilde{e}_{t-1}, \widetilde{e}_{t-2}, i \tilde{f}_{t-1}$} \\
\hline $\begin{array}{r}0.0974 \\
{[0.0371]} \\
\end{array}$ & $\begin{array}{r}0.2777 \\
{[0.0593]} \\
\end{array}$ & $\begin{array}{r}0.0101 \\
{[0.0010]} \\
\end{array}$ & $\begin{array}{r}0.8340 \\
{[0.0487]} \\
\end{array}$ & $\begin{array}{r}0.4414 \\
{[0.0679]} \\
\end{array}$ & $\begin{array}{r}0.3703 \\
{[0.0369]} \\
\end{array}$ & $\begin{array}{r}0.5061 \\
{[0.0694]}\end{array}$ & $\begin{array}{r}0.0707 \\
{[0.0091]} \\
\end{array}$ & $\begin{array}{r}0.4480 \\
{[0.0657]}\end{array}$ & $\begin{array}{r}0.6210 \\
{[0.0800]} \\
\end{array}$ \\
\hline \multicolumn{10}{|c|}{ Model 3, predictor variables: $\widetilde{r}_{t-1}, \widetilde{\theta}_{t-1}, \widetilde{e}_{t-1}, \tilde{i f}_{t-1}, \tilde{i f}_{t-2}$} \\
\hline $\begin{array}{r}0.0667 \\
{[0.0228]}\end{array}$ & $\begin{array}{r}0.2281 \\
{[0.0411]} \\
\end{array}$ & $\begin{array}{r}0.0099 \\
{[0.0009]}\end{array}$ & $\begin{array}{r}0.7863 \\
{[0.0565]}\end{array}$ & $\begin{array}{r}0.5166 \\
{[0.0761]}\end{array}$ & $\begin{array}{r}0.3985 \\
{[0.0377]} \\
\end{array}$ & $\begin{array}{r}0.5748 \\
{[0.0621]}\end{array}$ & $\begin{array}{r}\mathbf{0 . 0 8 3 2} \\
{[0.0092]}\end{array}$ & $\begin{array}{r}0.4198 \\
{[0.0643]}\end{array}$ & $\begin{array}{r}0.7266 \\
{[0.0836]}\end{array}$ \\
\hline \multicolumn{10}{|c|}{ Model 4, predictor variables: $\widetilde{r}_{t-1}, \widetilde{\theta}_{t-1}, \widetilde{e}_{t-1}, \tilde{f}_{t-1}, s \tilde{z} e_{t-1}$} \\
\hline $\begin{array}{r}0.1172 \\
{[0.0456]}\end{array}$ & $\begin{array}{r}0.3503 \\
{[0.0777]} \\
\end{array}$ & $\begin{array}{r}0.0101 \\
{[0.0009]}\end{array}$ & $\begin{array}{r}0.9059 \\
{[0.0315]}\end{array}$ & $\begin{array}{r}0.2340 \\
{[0.0550]}\end{array}$ & $\begin{array}{r}0.2296 \\
{[0.0321]} \\
\end{array}$ & $\begin{array}{r}0.4759 \\
{[0.0600]}\end{array}$ & $\begin{array}{r}0.0389 \\
{[0.0070]}\end{array}$ & $\begin{array}{r}0.4330 \\
{[0.0684]}\end{array}$ & $\begin{array}{r}0.6020 \\
{[0.0538]}\end{array}$ \\
\hline \multicolumn{10}{|c|}{ Model 5, predictor variables: $\widetilde{r}_{t-1}, \widetilde{\theta}_{t-1}, \widetilde{e}_{t-1}, l \widetilde{e} v_{t-1}, l \widetilde{e} v_{t-2}, i \tilde{f}_{t-1}$} \\
\hline $\begin{array}{r}0.0892 \\
{[0.0575]} \\
\end{array}$ & $\begin{array}{r}0.2667 \\
{[0.0982]} \\
\end{array}$ & $\begin{array}{r}0.0101 \\
{[0.0010]} \\
\end{array}$ & $\begin{array}{r}0.8269 \\
{[0.0889]}\end{array}$ & $\begin{array}{r}0.4475 \\
{[0.0765]} \\
\end{array}$ & $\begin{array}{r}0.3700 \\
{[0.0378]} \\
\end{array}$ & $\begin{array}{r}0.5218 \\
{[0.1136]}\end{array}$ & $\begin{array}{r}0.0721 \\
{[0.0162]}\end{array}$ & $\begin{array}{r}0.4456 \\
{[0.0952]}\end{array}$ & $\begin{array}{r}0.6210 \\
{[0.0863]}\end{array}$ \\
\hline \multicolumn{10}{|c|}{ Model 6, predictor variables: $\widetilde{r}_{t-1}, \widetilde{r}_{t-2}, \widetilde{r}_{t-3}, \widetilde{r}_{t-4}, \widetilde{\theta}_{t-1}, \widetilde{e}_{t-1}, i \tilde{f}_{t-1}$} \\
\hline $\begin{array}{r}0.1308 \\
{[0.0657]}\end{array}$ & $\begin{array}{r}0.3381 \\
{[0.1030]}\end{array}$ & $\begin{array}{r}0.0101 \\
{[0.0010]}\end{array}$ & $\begin{array}{r}0.8757 \\
{[0.0531]}\end{array}$ & $\begin{array}{r}0.3796 \\
{[0.0742]}\end{array}$ & $\begin{array}{r}0.3350 \\
{[0.0404]}\end{array}$ & $\begin{array}{r}0.4552 \\
{[0.0890]}\end{array}$ & $\begin{array}{r}0.0580 \\
{[0.0123]}\end{array}$ & $\begin{array}{r}0.4340 \\
{[0.0680]}\end{array}$ & $\begin{array}{r}0.4881 \\
{[0.0899]}\end{array}$ \\
\hline \multicolumn{10}{|c|}{ Model 7, predictor variables: $\widetilde{r}_{t-1}, \widetilde{r}_{t-2}, \widetilde{r}_{t-3}, \widetilde{r}_{t-4}, \widetilde{\theta}_{t-1}, \widetilde{\theta}_{t-2}, \widetilde{e}_{t-1}, \widetilde{e}_{t-2}, \tilde{i f}_{t-1}, \tilde{i f}_{t-2}$} \\
\hline $\begin{array}{r}0.1766 \\
{[0.0900]}\end{array}$ & $\begin{array}{r}0.4008 \\
{[0.1312]}\end{array}$ & $\begin{array}{r}0.0099 \\
{[0.0009]}\end{array}$ & $\begin{array}{r}0.8964 \\
{[0.0446]}\end{array}$ & $\begin{array}{r}0.3776 \\
{[0.0682]}\end{array}$ & $\begin{array}{r}0.3407 \\
{[0.0417]}\end{array}$ & $\begin{array}{r}0.4050 \\
{[0.0865]}\end{array}$ & $\begin{array}{r}0.0536 \\
{[0.0120]}\end{array}$ & $\begin{array}{r}0.4593 \\
{[0.0700]}\end{array}$ & $\begin{array}{r}0.5435 \\
{[0.0822]}\end{array}$ \\
\hline
\end{tabular}




\section{Figure 1. Time-series evolution of variables.}

The figure graphs the time series of cross-sectional percentiles $\left(5^{\text {th }}, 25^{\text {th }}, 50^{\text {th }}, 75^{\text {th }}, 95^{\text {th }}\right)$ for the following variables: $\log$ return, $r$; log return on equity, $e^{G A A P}$; fraction of institutional ownership, if ; and $\log$ book-to-market, $\theta$. For a more detailed definition of the variables and data, see Appendix B.

Figure 2. Price response to shocks, pooled WLS.

The figure contains two impulse-response functions computed from the VAR system of Table III, Panel A. The first graph shows the cumulative response of market-adjusted log returns to typical 25 percent cash-flow news. The typical 25 percent cash-flow news is induced by setting the VAR-error vector to a constrained maximum likelihood value, imposing the constraint that cash-flow news equals 0.25 .

The second graph shows the cumulative response of market-adjusted log returns to a 25 percent unexpected return in the absence of cash-flow news. The 25 percent return shock is induced by setting the first element of the VAR-error vector to 0.25 . The other elements of the VAR-error vector are set to their conditional expectations, conditional on the first element being equal to 0.25 and cash-flow news equal to zero.

Dashed lines denote $+/-2$ standard-error bounds, calculated using the jackknife.

Figure 3. Price response to shocks, RCM.

The figure contains two impulse-response functions computed from the firm-specific VAR systems. First, the impulse-response functions are computed for all firms. Then, for each horizon, the median response is plotted with solid line. $10^{\text {th }}$ and $90^{\text {th }}$ percentiles are plotted with dashed lines.

The first graph shows the cumulative response of market-adjusted log returns to typical 25 percent cash-flow news. The typical 25 percent cash-flow news is induced by setting the VAR-error vector to a constrained maximum likelihood value, imposing the constraint that cash-flow news equals 0.25 .

The second graph shows the cumulative response of market-adjusted log returns to a 25 percent unexpected return in the absence of cash-flow news. The 25 percent return shock is induced by setting the first element of the VAR-error vector to 0.25 . The other elements of the VAR-error vector are set to their conditional expectations, conditional on the first element being equal to 0.25 and cash-flow news equal to zero.

Figure 4. Response of institutional ownership to shocks, pooled WLS.

The figure contains two impulse-response functions computed from the VAR system of Table III Panel A. The first graph shows the response of institutional ownership to typical 25 percent cash-flow news. The typical 25 percent cash-flow news is induced by setting the VAR-error vector to a constrained maximum likelihood value, imposing the constraint that cash-flow news equals 0.25 .

The second graph shows the response of institutional ownership to a 25 percent unexpected return in the absence of cash-flow news. The 25 percent return shock is induced by setting the first element of the VAR-error vector to 0.25 . The other elements of the VAR-error vector are set to their conditional expectations, conditional on the first element being equal to 0.25 and cash-flow news equal to zero.

Dashed lines denote $+/-2$ standard-error bounds, calculated using the jackknife. 
Figure 5. Response of institutional ownership to shocks, RCM.

The figure contains two impulse-response functions computed from the firm-specific VAR systems. First, the impulse-response functions are computed for all firms. Then, for each horizon, the median response is plotted with solid line. $10^{\text {th }}$ and $90^{\text {th }}$ percentiles are plotted with dashed lines.

The first graph shows the response of institutional ownership to typical 25 percent cash-flow news. The typical 25 percent cash-flow news is induced by setting the VAR-error vector to a constrained maximum likelihood value, imposing the constraint that cash-flow news equals 0.25 .

The second graph shows the response of institutional ownership to a 25 percent unexpected return in the absence of cash-flow news. The 25 percent return shock is induced by setting the first element of the VAR-error vector to 0.25 . The other elements of the VAR-error vector are set to their conditional expectations, conditional on the first element being equal to 0.25 and cash-flow news equal to zero.

Figure 6. Results for size groups.

The top two figures graph the results for different size quintiles from Table VI Panel A. The upper-left figure plots the regression coefficient of return on cash-flow news, and the upper-right figure plots the regression coefficient of institutional-ownership shock on cash-flow news.

The bottom two figures graph the results for different size quintiles from Table VI Panel B. The lower-left figure plots the regression coefficient of return on cash-flow news, and the lower-right figure plots the regression coefficient of institutional-ownership shock on cash-flow news.

Dashed lines denote $+/-2$ standard-error bounds, calculated using the jackknife.

\section{Figure 7. Conditional momentum and reversal}

The figure shows two impulse-response functions computed from the VAR system of Table III Panel A. The first graph shows the price response to one-standard-deviation positive return shock and one-standard-deviation positive institutional-ownership shock. The shocks are induced by setting the VAR-error vector to its constrained maximum likelihood value, imposing the constraints that unexpected return equals 0.32 and institutional-ownership shock 0.10 (one-standard-deviation shocks both).

The second graph shows the price response to one-standard-deviation positive return shocks and one-standard-deviation negative institutional-holdings shock. In the second graph, the VAR-error vector is set to its constrained maximum likelihood value, imposing the constraints that unexpected return equals 0.32 and institutional-ownership shock -0.10 .

Dashed lines denote $+/-2$ standard-error bounds, calculated using the jackknife.

\section{Figure 8. Trade-off between expected return and tracking error}

The figure plots the portfolio-strategy opportunity set and the trade-off between expected return and tracking error generated by combining CRSP VW portfolio and an investment strategy.

The first strategy (denoted with a solid line) combines the CRSP VW portfolio and the cash-flownews portfolio from Table VIII, i.e., a portfolio that goes long in stocks that have experienced positive cash-flow news during the previous year and goes short in stocks that have experienced negative cashflow news during the previous year. In this portfolio, the stocks have weights proportional to their past cash-flow news. The cash-flow-news series are estimated using past data only, using an annual firstorder VAR with market-adjusted log return, ROE, and book-to-market in the state vector. The VAR data are the 1954-1998 CRSP-COMPUSTAT intersection used by Vuolteenaho (2002).

The second strategy (denoted with a dotted line) combines the CRSP VW portfolio and the difference between the aggregate institutional portfolio and the CRSP VW portfolio. Investing one dollar 
in the CRSP VW market portfolio and one dollar in this difference portfolio recovers the aggregate institutional portfolio (denoted by a circle on the dotted line).

The third strategy (denoted by a dashed line) combines the CRSP VW portfolio and the cash-flow news portfolio, but constraining the total weight in any security to be nonnegative and thus not allowing short positions. At zero, the solid line and dashed line have the same slope.

The fourth strategy (denoted by a dash-dotted line) combines the CRSP VW portfolio and the difference between the aggregate institutional portfolio and the CRSP VW market portfolio, but constraining the total weight in any security to be nonnegative.

The vertical axis of the graph is the annualized average return difference between the portfolio strategy and the CRSP VW market portfolio. The horizontal axis is the annualized standard deviation of the return difference between the strategy and the CRSP VW market portfolio. Moments are estimated from 7/1981-12/1998 monthly returns.

\section{Figure 9. Impulse responses using simple returns and directly computed cash-flow news.}

The figure contains two impulse-response functions to directly computed cash-flow news. The VAR specification has the structure:

$$
z_{i, t}=\Gamma z_{i, t-1}+u_{i, t}, \quad \Sigma=E\left(u_{i, t} u_{i, t}^{\prime}\right)
$$

The VAR state vector includes the market-adjusted simple stock return, market-adjusted log book-tomarket ratio, market-adjusted log GAAP profitability, market-adjusted log clean-surplus profitability, and market-adjusted fraction of institutional ownership. Define $e 4^{\prime} \equiv\left[\begin{array}{llll}0 & \cdots & 0 & 1\end{array}\right]$. Direct cash-flow news can be conveniently expressed as $e 4^{\prime}(I-\rho \Gamma)^{-1} u_{i, t}$.

The first graph shows the response of expected simple returns to typical 25 percent cash-flow news. The typical 25 percent cash-flow news is induced by setting the VAR-error vector to a constrained maximum likelihood value, imposing the constraint that cash-flow news equals 0.25 .

The second graph shows the response of institutional ownership to a typical 25 percent cash-flow news. The typical 25 percent cash-flow news is induced by setting the VAR-error vector to a constrained maximum likelihood value, imposing a constraint cash-flow news equals 0.25 .

Dashed lines denote $+/-2$ standard-error bounds, calculated using the jackknife. 


\section{Figure 1: Time-series evolution of variables}
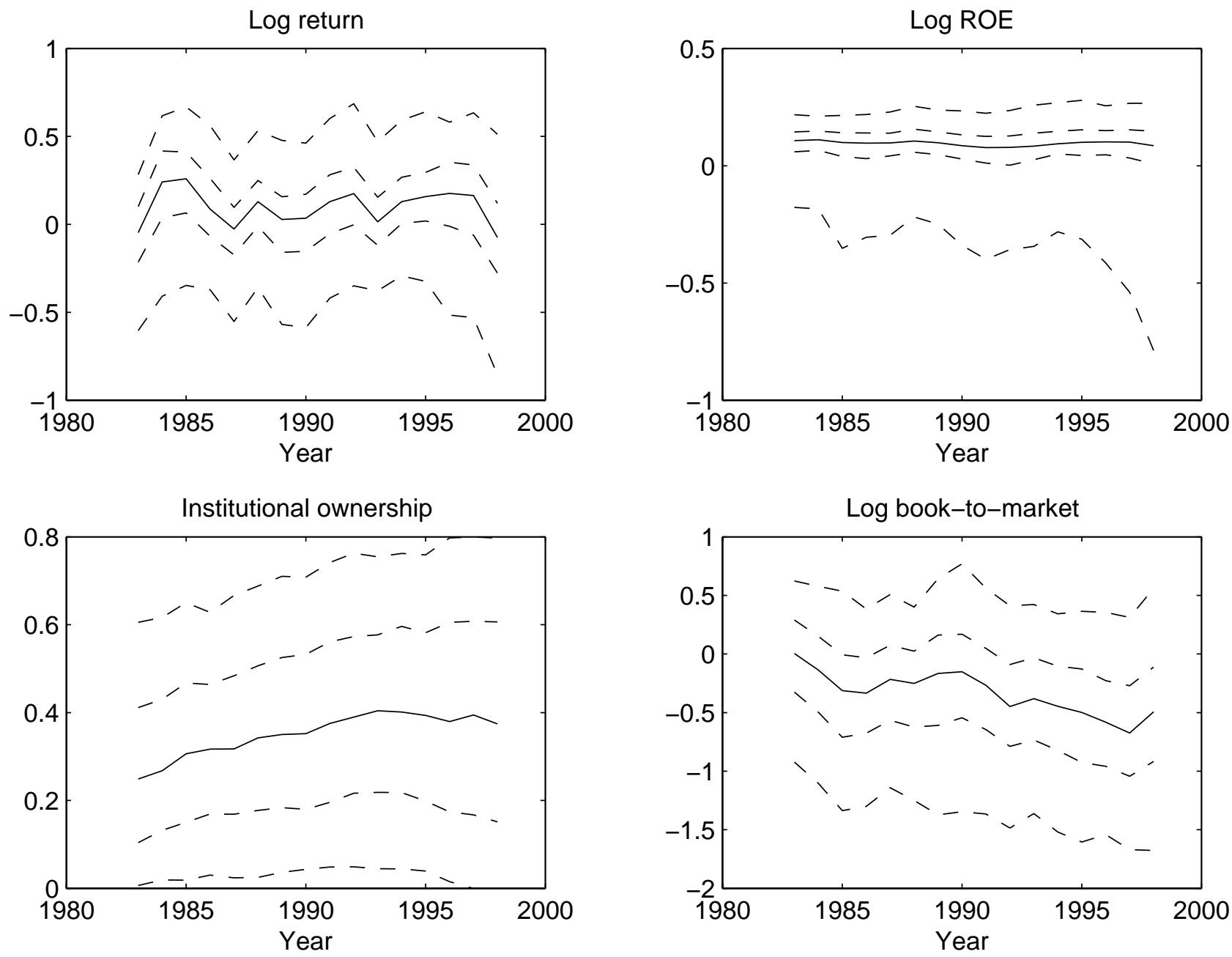
Figure 2: Price response to shocks, pooled WLS
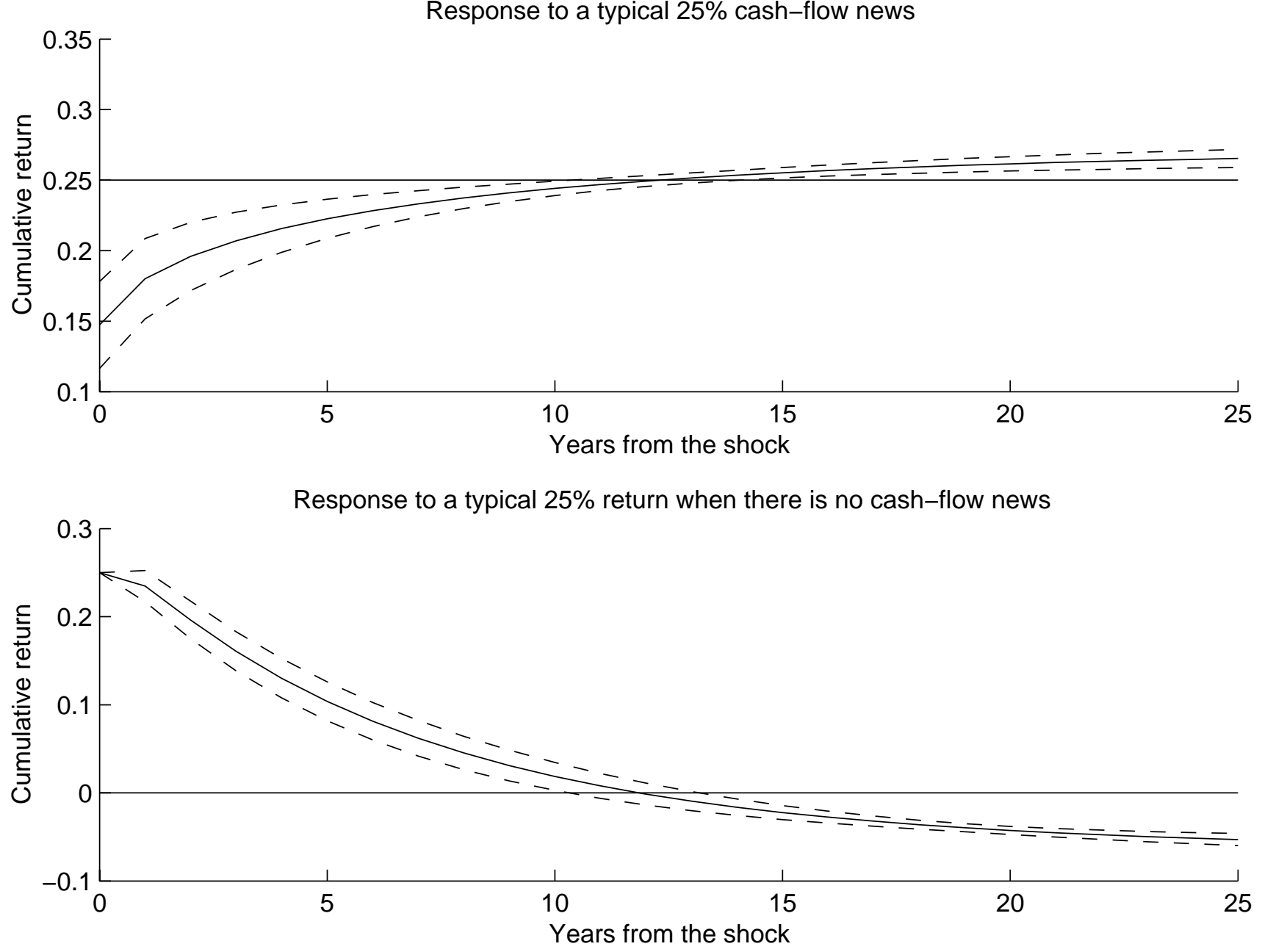
Figure 3: Price response to shocks, RCM

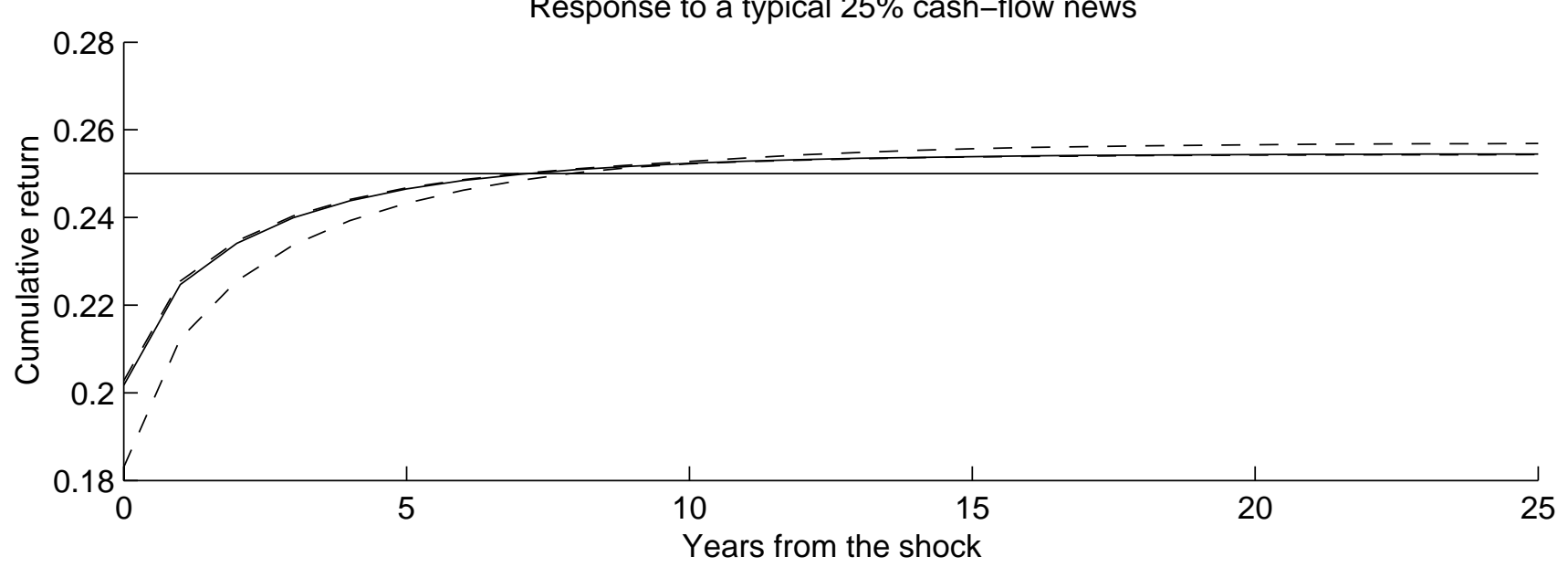

Response to a typical $25 \%$ cash-flow news

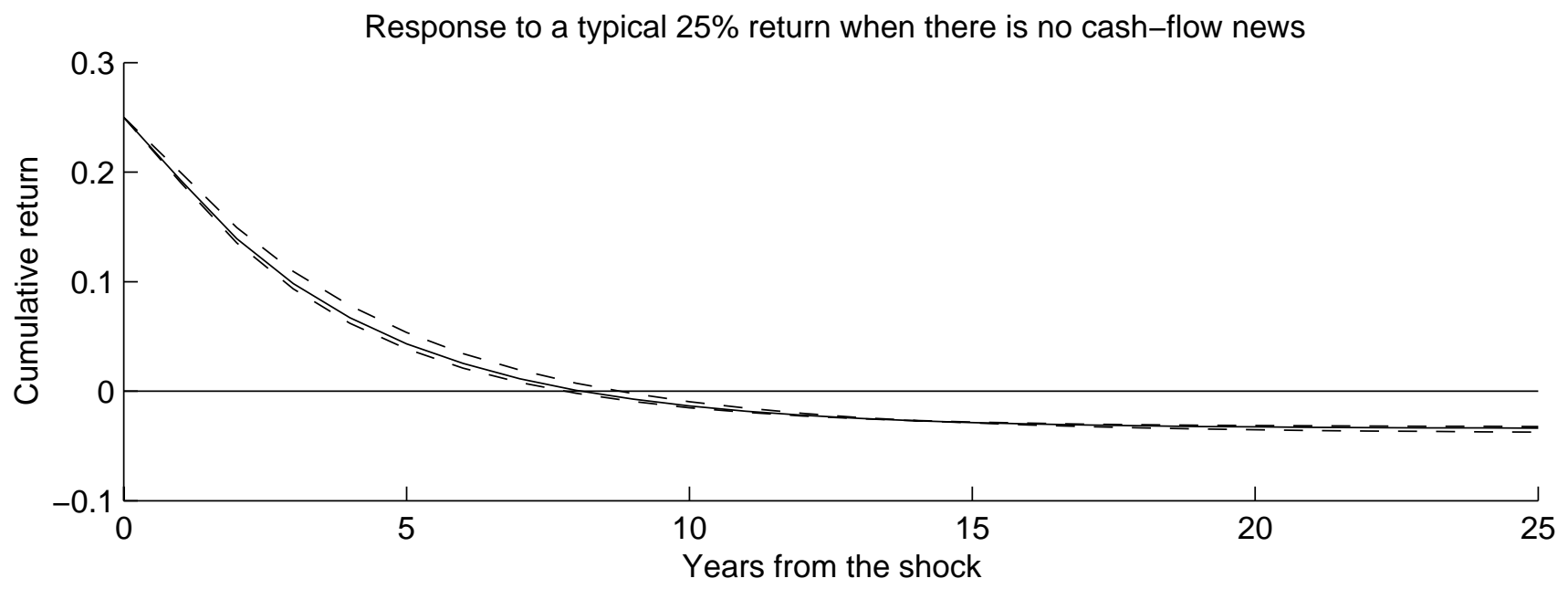


Figure 4: Response of institutional ownership to shocks, pooled WLS
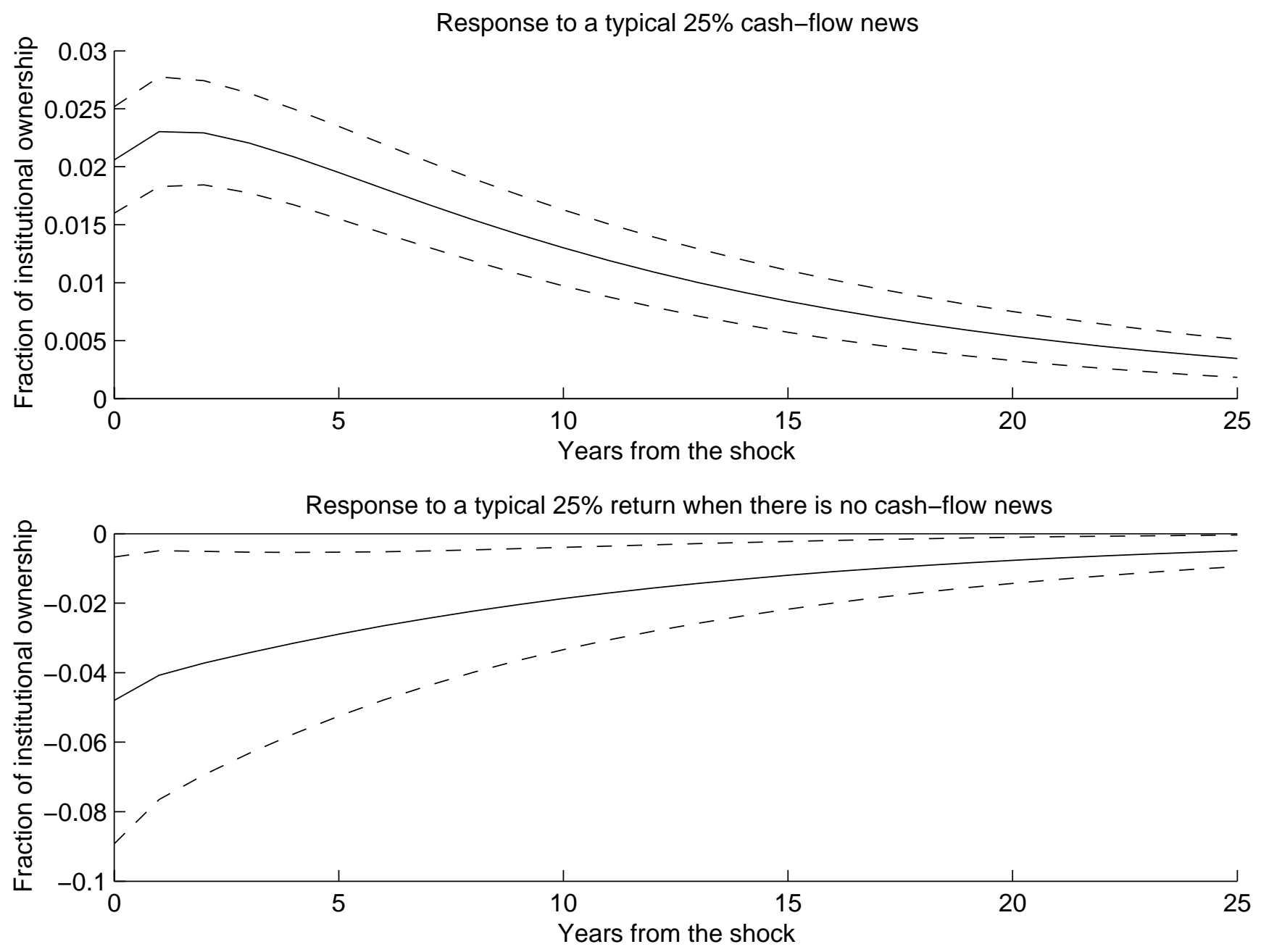
Figure 5: Response of institutional ownership to shocks, RCM
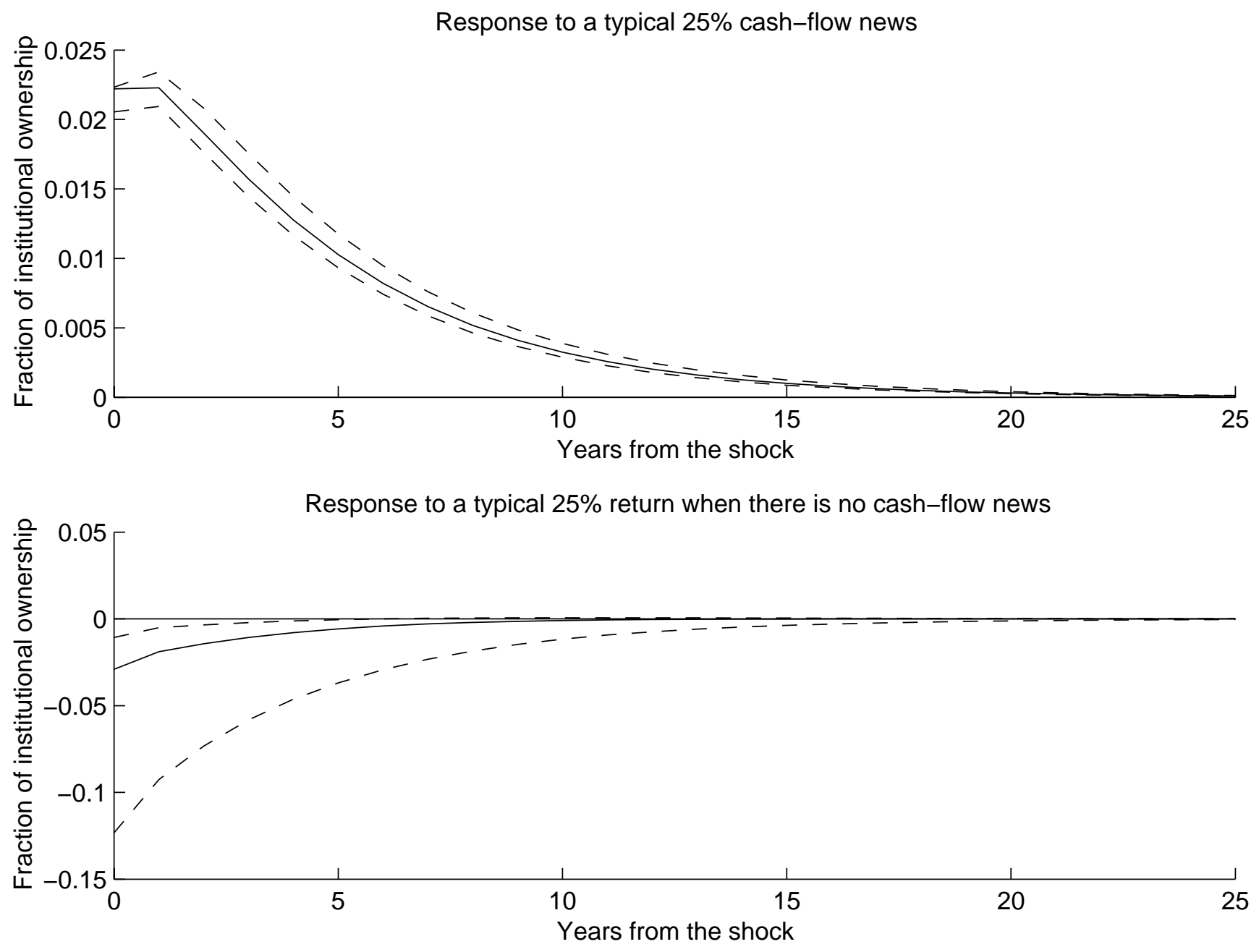


\section{Figure 6: Results for size groups}
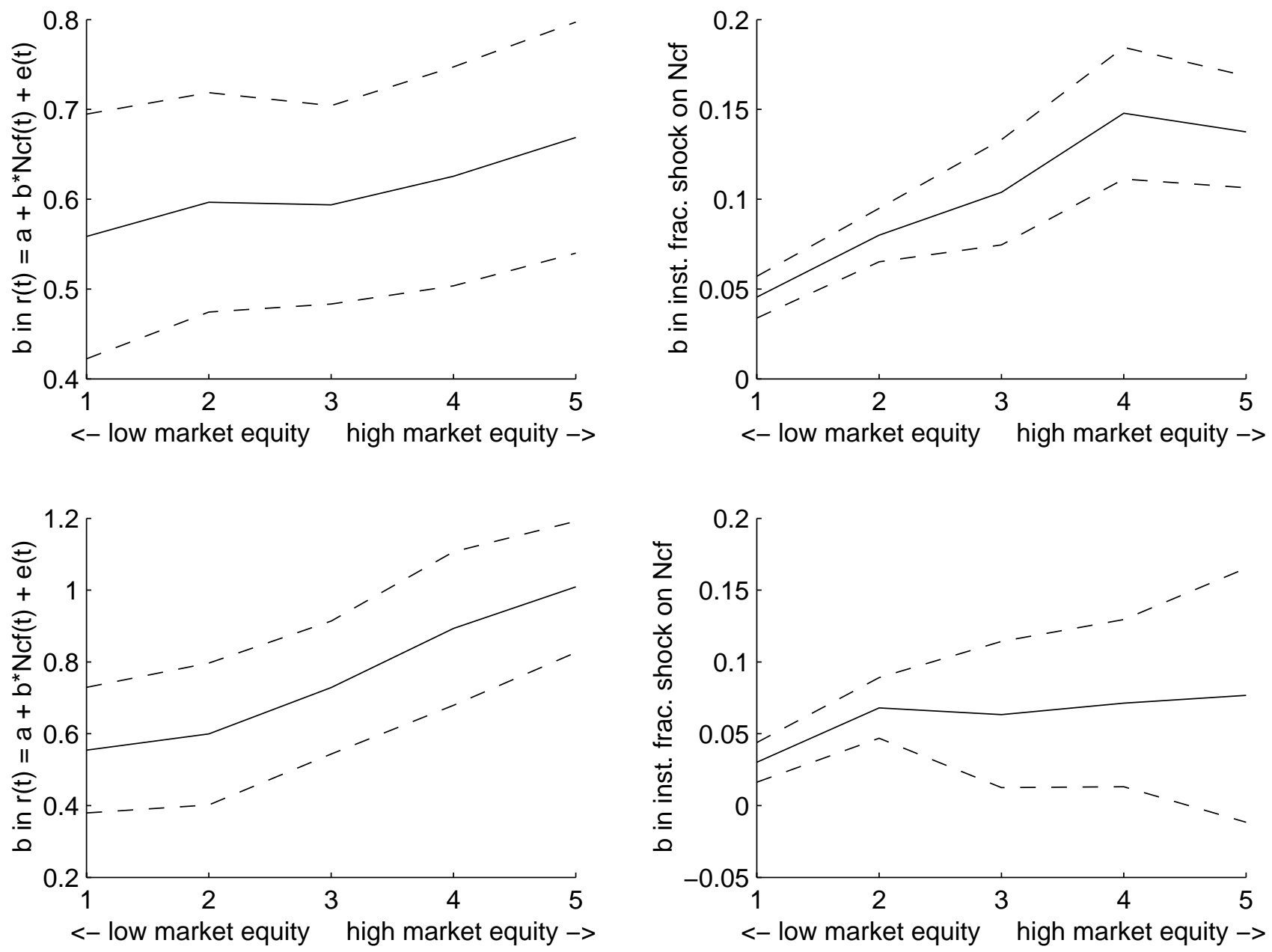


\section{Figure 7: Conditional momentum and reversal}
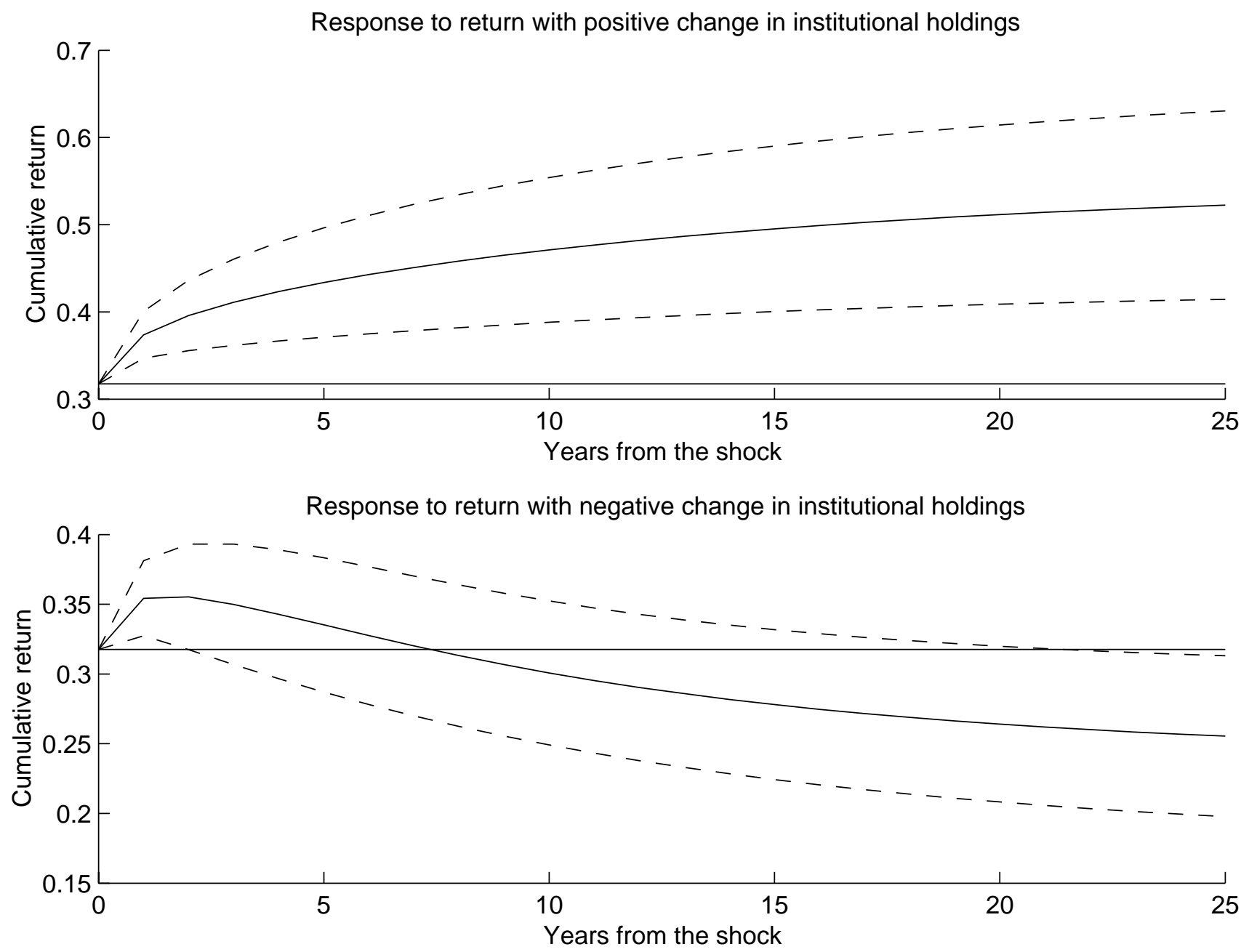
Figure 8: Trade-off between expected return and tracking error

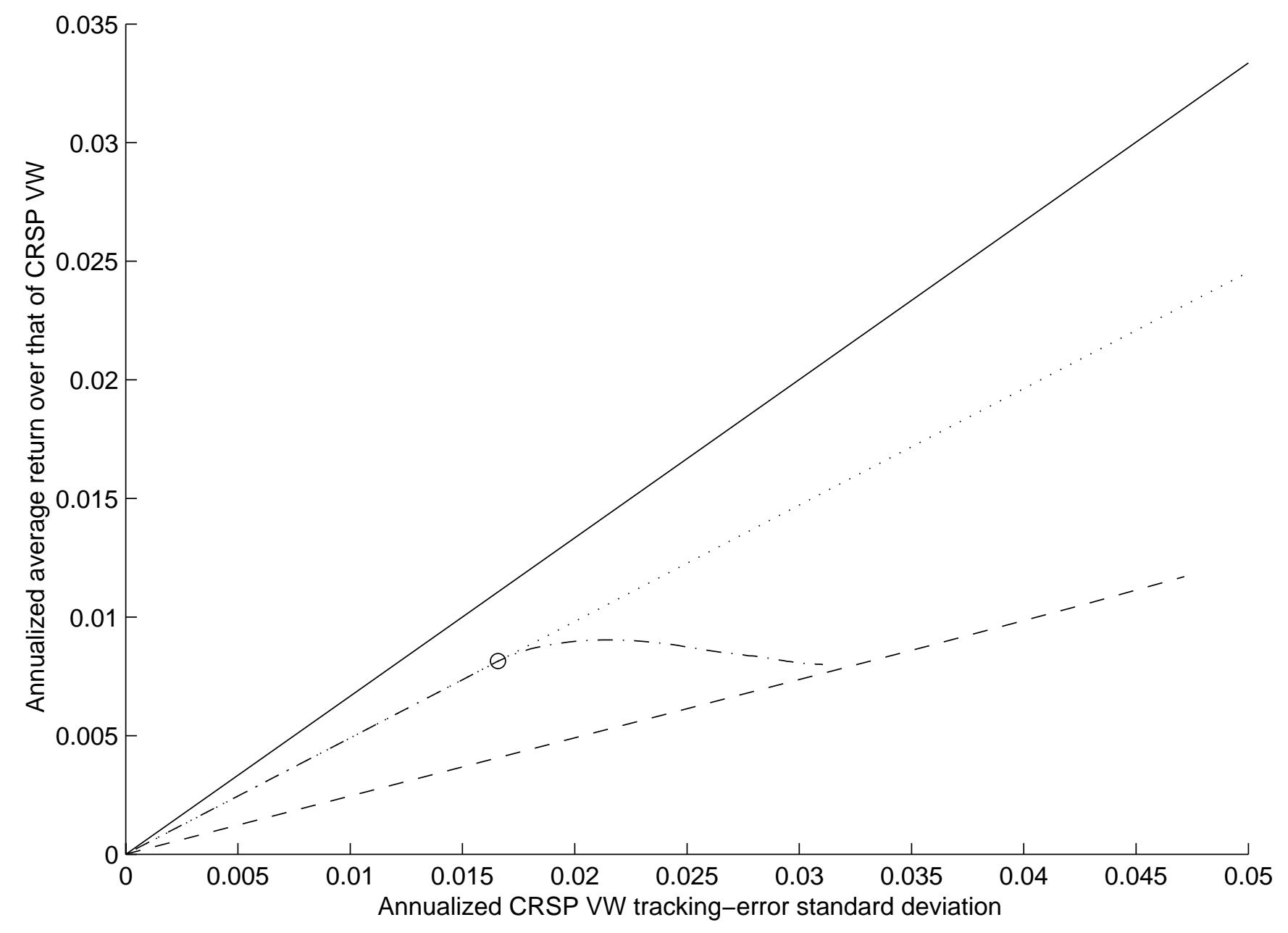


Figure 9: Impulse responses using simple returns and directly computed cash-flow news
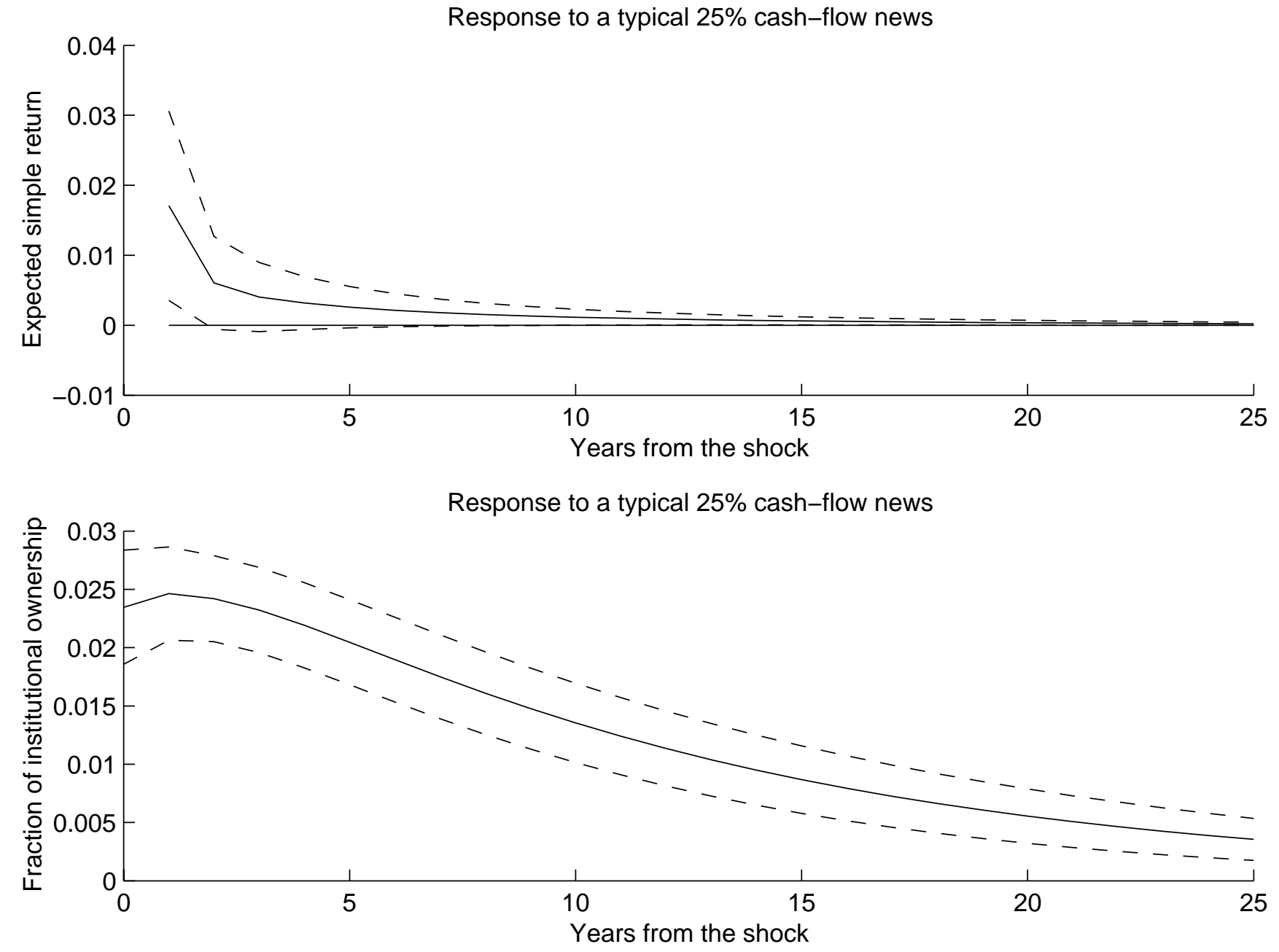
${ }^{1}$ Bernard and Thomas $(1989,1990)$ study earnings surprises and Michaely, Womack, and Thaler (1995) dividend initiations and omissions. For a summary of empirical papers that find a drift subsequent to a public announcement, see Daniel, Hirshleifer, and Subrahmanyam (1998).

2 There is an apparent interaction effect in Panel B of Table I. When we pool Table I Panel B's disaggregated data and regress the change in institutional holdings on market-adjusted log stock return and cash-flow news, we get an $\mathrm{R}^{2}$ of $14.46 \%$. Inclusion of an interaction term in the regression leaves the return and cash-flow-news coefficients virtually unchanged and increases the $\mathrm{R}^{2}$ only by 31 basis points to $14.77 \%$. Although the interaction term is statistically significant, these $\mathrm{R}^{2} \mathrm{~s}$ indicate that it is still only a second-order effect. Furthermore, most of the interaction effect is most likely due to size patterns discussed in Section I.F.

${ }^{3}$ Market-adjusted or benchmark-adjusted returns can be decomposed, as well. Apply equation (1) to individual firm-level stock return and market return separately, and subtract the latter equation from the former. As a result, the (unexpected) market-adjusted stock return can be decomposed into components due to above-market expected stock returns and ROEs. When we refer specifically to market-adjusted quantities, we modify the notation by a tilde. For example, $\widetilde{r}_{t}$ denotes the market-adjusted log stock return.

${ }^{4}$ We would like to thank John Heaton for helpful discussions on this point.

${ }^{5}$ Unfortunately, maximum-likelihood estimation of a specification with fat-tailed measurement equation (7) errors is likely to be computationally costly. Bayesian approach and simulation-based Markov chain estimation may be a computationally less costly and more flexible alternative to our maximum-likelihood approach. We do not explore these methods, however.

${ }^{6}$ In the case of market-adjusted returns and homogenous VAR, this typical risk premium is identically zero. For firm-specific VAR parameters obtained from the RCM, the typical risk premium for a firm is that firm's unconditional expected market-adjusted return.

${ }^{7}$ We have also experimented with a random-coefficient model where a firm-size measure is included as an instrument in the estimation of the VAR transition matrix. A simple way to include an instrument in the RCM procedure is to let the expected coefficients to be functions of the instrument: $\operatorname{vec}\left(\left[\mathrm{A}_{i} \Gamma_{i}\right]^{\prime}\right) \sim$ i.i.d.N $\left(\gamma_{0}+\right.$ Instrumet $\left._{i} \times \gamma_{1}, \Omega\right)$. The system can be estimated with a minor modification 
of equation (A3.6). The empirical results of our experiments typically fall between the commontransition-matrix and constant-group-assignment results, closer to the latter.

${ }^{8}$ Chevalier and Ellison (1999) show that such tracking-error constraints are especially important for young portfolio managers.

${ }^{9}$ Dimson and Jackson (2001) document that the UK pension funds have stricter limits: "The National Association of Pension Funds, for example, gives the following advice: 'Trustees will set their fund managers targets relating to the benchmarks. These targets may include the following items: i) a target outperformance level; ii) a timescale over which [this] is expected to be achieved, e.g. rolling three year periods; iii) possible downside targets, e.g., not to outperform the benchmark in any one year by more than 2 [percent]." Another example is the Norwegian Government Petroleum Fund, which imposes an explicit limit of 1.5 percent tracking-error standard deviation on managers.

${ }^{10}$ The delisting-return assumptions are based on Shumway's (1997) results. Shumway tracks a sample of firms whose delisting returns are missing from the CRSP data and finds that performance-related delistings are associated with a significant negative return, on average approximately -30 percent. This assumption is unimportant to our final results, however. 